\title{
Genetic constraints for thermal coadaptation in Drosophila subobscura
}

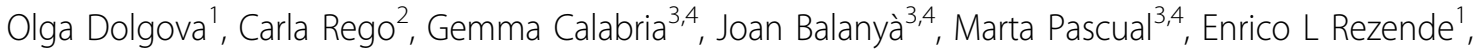 \\ Mauro Santos ${ }^{1 *}$
}

\begin{abstract}
Background: Behaviour has been traditionally viewed as a driver of subsequent evolution because behavioural adjustments expose organisms to novel environments, which may result in a correlated evolution on other traits. In Drosophila subobscura, thermal preference and heat tolerance are linked to chromosomal inversion polymorphisms that show parallel latitudinal clines worldwide, such that "cold-climate" ("warm-climate") chromosome arrangements collectively favour a coherent response to colder (warmer) settings as flies carrying them prefer colder (warmer) conditions and have lower (higher) knock out temperatures. Yet, it is not clear whether a genetic correlation between thermal preference and heat tolerance can partially underlie such response.

Results: We have analyzed the genetic basis of thermal preference and heat tolerance using isochromosomal lines in D. subobscura. Chromosome arrangements on the $\mathrm{O}$ chromosome were known to have a biometrical effect on thermal preference in a laboratory temperature gradient, and also harbour several genes involved in the heat shock response; in particular, the genes $\mathrm{Hsp68}$ and Hsp70. Our results corroborate that arrangements on chromosome $\mathrm{O}$ affect adult thermal preference in a laboratory temperature gradient, with cold-climate $\mathrm{O}_{\text {st }}$ carriers displaying a lower thermal preference than their warm-climate $\mathrm{O}_{3+4}$ and $\mathrm{O}_{3+4+8}$ counterparts. However, these chromosome arrangements did not have any effect on adult heat tolerance and, hence, we putatively discard a genetic covariance between both traits arising from linkage disequilibrium between genes affecting thermal preference and candidate genes for heat shock resistance. Nonetheless, a possible association of juvenile thermal preference and heat resistance warrants further analysis.
\end{abstract}

Conclusions: Thermal preference and heat tolerance in the isochromosomal lines of $D$. subobscura appear to be genetically independent, which might potentially prevent a coherent response of behaviour and physiology (i.e., coadaptation) to thermal selection. If this pattern is general to all chromosomes, then any correlation between thermal preference and heat resistance across latitudinal gradients would likely reflect a pattern of correlated selection rather than genetic correlation.

\section{Background}

Ectotherms exhibit a suite of behavioural and physiological strategies to cope with spatiotemporal variation in ambient temperature [1]. For instance, behavioural adjustments (e.g. modifying daily activity patterns and selecting favourable microclimates; [2]) can buffer the impact of sub-optimal temperatures, and are the main means of thermoregulation in small insects [3-5]. Although such adjustments can enable ectotherms to

\footnotetext{
* Correspondence: mauro.santos@uab.es

'Departament de Genètica i de Microbiologia, Grup de Biologia Evolutiva (GBE), Universitat Autònoma de Barcelona, 08193 Bellaterra (Barcelona), Spain Full list of author information is available at the end of the article
}

maintain relatively constant body temperatures $\left(T_{\mathrm{b}}\right)$ at different seasons and/or latitudes [2,6], the observation of cyclical seasonal changes in genetic markers putatively related to thermal adaptation $[7,8]$ and the clinal variation in thermal stress tolerance in some Drosophila species [9-11] suggest that behavioural thermoregulation may be insufficient to fully compensate shifts in environmental temperature [12].

If behavioural thermoregulation is not fully compensatory and climate variation influences the actual $T_{\mathrm{b}}$ and physiological performance of organisms distributed over broad latitudinal ranges (i.e., performance falls below its optimum during cooling and warming), then temperature

\section{Biomed Central}


is more than just a key environmental factor that affects development, growth, and survival of individuals [13,14]: it is likely the main selective agent that drives - directly or indirectly - the evolution of clinal patterns in genetic, phenotypic, and life history traits. Furthermore, the divergence of thermal optima in the different subpopulations according to the $T_{\mathrm{b}}$ experienced by the organism is expected to bolster a covariance between behavioural shifts (thermal preference) and performance $[6,15]$. This is related to the idea of "coadaptation" [16], where natural selection is supposed to favour the harmonious adjustment among the suite of (co-)evolving traits $[7,17]$. Parallel clines on different continents or along independent temperature gradients can thus offer an invaluable opportunity to study thermal coadaptation since the role of temperature in driving those clines is quite compelling.

Some widespread latitudinal clines in Drosophila also provide an additional advantage for studies of thermal coadaptation: there is a relatively well-known historical record following the invasion of a new geographical region (e.g. $[18,19])$. Perhaps the best example is that of Drosophila subobscura, a native Palaearctic species that invaded the Americas about 30 years ago, and spread rapidly on both South and North America. Clinal patterns for phenotypic traits and genetic polymorphisms emerged very rapidly during these two independent colonization events [20-22]. For instance, North American populations soon evolved decreased desiccation resistance with increasing latitude as expected, which matches the pattern found in Old World populations and suggests that strong selection for thermal-related traits along latitudinal gradients is taking place. On the other hand, in South America this trait shows the opposite pattern: higher desiccation tolerance is observed in colder areas [23]. Contrasting outcomes were also observed for other clinally varying traits - wing cell size and cell number [24], and wing shape $[20,25]$ - where the role of temperature remains elusive, which apparently suggests that selective pressures vary in the different clines. An alternative explanation, however, is that evolution can sometimes be constrained by antagonistic genetic correlations (i.e., genetic correlations among traits that are not in accord with the direction of selection [26,27]) arising from linkage disequilibrium between alleles at different loci, and patterns of linkage disequilibrium can vary among populations or seasons $[28,29]$. In this context, we now know that contrasting wing shape clines in $D$. subobscura came out as a correlated response of the world-wide parallel inversion clines [21] because inversion-shape relationships in native and colonizing populations are opposite (presumably due to the different associations between inversions and particular alleles which influence the trait), probably as a result of the bottleneck effect that occurred during the colonization of America [30]. Besides, different patterns of linkage disequilibrium could result from variability in migration rates between genetically differentiated populations in the various latitudinal clines [31]. In summary, conflicting outcomes between old and rapidly evolving new clines should probably not be viewed as a nuisance, but as reminder that an appropriate knowledge of the underlying genetic architecture is required to further understand why (or why not) these inconsistencies arise. More specifically, if behaviour "drives" the subsequent parallel evolution in morphology and physiology as predicted ([6]; but see [32]), it is essential to analyze the genetic basis of thermal preference and temperaturerelated traits to see whether or not thermal coadaptation can happen along a cline.

We have recently undertaken a within-population large-scale study to analyze the association between chromosomal inversion polymorphisms that show parallel latitudinal clines in native and colonizing populations of $D$. subobscura, with the thermal preferences $\left(T_{\mathrm{p}}\right.$ : the preferred body temperature in a laboratory thermal gradient, which we expect to correlate with the thermal optimum for performance; [33]) and knock out temperatures $\left(T_{\mathrm{ko}}\right.$ : the temperature required to knock out a fly in a waterbath) of their carriers [34]. The main results can be summarized as follows: $(i)$ flies carrying "cold-adapted" or "cold-climate" chromosome arrangements (i.e., those chromosome arrangements in all five major acrocentric chromosomes that show a negative correlation coefficient with maximum temperatures along the cline, or a positive correlation coefficient with latitude in Palaearctic populations; [35,36]) prefer a lower $T_{\mathrm{p}}$ and had a lower $T_{\mathrm{ko}}$, in accordance with the natural patterns; (ii) different chromosomes were responsible for the bulk of the genetic variation in $T_{\mathrm{p}}$ (chromosomes $\mathrm{A}$ and $\mathrm{O}$ ) and $T_{\mathrm{ko}}$ (chromosome E); and (iii) $T_{\mathrm{p}}$ and $T_{\mathrm{ko}}$ were phenotypically uncorrelated, which agrees with the observation that different independently segregating chromosomes were mainly responsible for the corresponding associations. Taken at a face value, behavioural thermoregulation and performance were indeed "coadapted" in the sense that cold-climate (warm-climate) chromosome arrangements collectively favour a coherent response to colder (warmer) environments, but this was not due to a genetic covariance of behaviour and physiology. There were, however, two potential limitations in the study. First, each individual fly was scored for only one chromosome of its diploid set and, hence, dominance effects (if any) where hidden in the analysis. Second, both intraand interchromosomal contributions were mixed because the assayed flies had the genetic background from the sampled wild population. Although it might be argued that this protocol is somehow closer to what happens in nature, these uncontrolled factors might have precluded 
a better characterization of the underlying genetic effects. Accordingly, although the amount of genetic variation on $T_{\mathrm{p}}$ and $T_{\mathrm{ko}}$ explained by the combined effect of all chromosomes carrying at least one cold-climate gene arrangement was statistically significant, it only accounted for $1 \%$ of the total phenotypic variation [34].

Here we examine if $T_{\mathrm{p}}$ and $T_{\mathrm{ko}}$ are genetically correlated and might evolve in a coherent fashion in response to selection; i.e., whether behaviour and physiology are coadapted at the genetic level. We take advantage of the fact that the polymorphic inversions on chromosome $\mathrm{O}$ appear to be associated with behavioural thermoregulation in D. subobscura [34], and that this is the only chromosome that can be used to measure the expression of associated traits in replicated inbred and outbred genotypes. Namely, chromosome $\mathrm{O}$ is the only one for which a balancer stock (Va/Ba: Varicose/Bare; [37]) is available (a balancer is a specially constructed chromosome that carries a dominant morphological marker that is homozygous lethal and multiple inversions to suppress recombination). This is the longest chromosome in $D$. subobscura (190 cM which correspond to approximately $31 \mathrm{Mb}$ [38]), and is homologous to arm 3R in D. melanogaster $[39,40]$. Some chromosome arrangements $\left(\mathrm{O}_{\text {st }}\right.$ and $\mathrm{O}_{3+4}$ ) show conspicuous northwest-southwest latitudinal clines in Palaearctic populations (Figure 1a). Chromosome $\mathrm{O}$ harbours several genes involved in the heat shock response [41]; in particular, gene Hsp68 (located in section $\mathrm{O}(89 \mathrm{~A})[42,43]$ and relatively close to the proximal breakpoint of inversion $\mathrm{O}_{8}$ [44]), and gene Hsp70 (located in section $\mathrm{O}(94 \mathrm{~A})[42,43]$ and included inside the warm-climate chromosomal arrangement $\mathrm{O}_{3+4}$, and close to the distal breakpoint of inversion $\mathrm{O}_{8}$ [44]) (Figure 1b). Hsp70 appears to be the primary protein involved in thermotolerance in D. melanogaster [45] though apparently not in other Drosophila species [46] -, and $H s p 70$ allele frequencies show latitudinal clines and change in response to thermal evolution in the laboratory [47]. In addition, correlated responses to selection for knock down resistance at $39^{\circ} \mathrm{C}$ have also been found for Hsp68 in D. melanogaster [48].

Previous work also showed that D. subobscura flies carrying $\mathrm{O}$ chromosomes derived from replicated thermal lines $[49,50]$ that had evolved in the laboratory at warm temperatures $\left(22^{\circ} \mathrm{C}\right)$ had a higher total net fitness than its cold-adapted $\left(13^{\circ} \mathrm{C}\right)$ counterparts; that is, a significant shift in thermal optima was observed [51]. All in all, it seems that there is indeed room for the coevolution of behaviour and physiological tolerance in $D$. subobscura. However, we show here that thermal preference and heat tolerance appear to be genetically independent. Therefore, any latitudinal correlation between both traits would likely reflect a pattern of correlated selection across populations rather than within-population genetic correlations.

\section{Experimental settings}

In south-western European populations, the most frequent chromosome arrangements for chromosome $\mathrm{O}$ are $\mathrm{O}_{\mathrm{st}}, \mathrm{O}_{3+4}, \mathrm{O}_{3+4+7}$, and $\mathrm{O}_{3+4+8}$ [52]. The first two arrangements show a clear contrasting clinal pattern in original Palaearctic populations, with $\mathrm{O}_{\text {st }}$ increasing and $\mathrm{O}_{3+4}$ decreasing in frequency with increasing latitude [35,56] (Figure 1a). Arrangement $\mathrm{O}_{3+4+8}$ is also interesting because in historical times it was mainly restricted to the Mediterranean region, being the most abundant chromosomal arrangement in northern Africa [53]. However, in the last decades its distribution has changed dramatically and recent surveys revealed frequencies as high as $22.6 \%$ in Groningen, Netherlands, where it was previously absent $[22,54]$. Six independent isochromosomal lines for each of these three arrangements (i.e., $\mathrm{O}_{j}^{1}, \ldots, \mathrm{O}_{j}^{6} ; j=$ st, $\left.3+4,3+4+8\right)$ were used in the present experiments. Extensive genetic differentiation of up to $4 \mathrm{Mb}$ (i.e., about $15 \%$ of the euchromatic portion) has been detected among these arrangements [55]. In other words, there are compelling reasons to think that the chromosome arrangements used in this work are genetically differentiated for $\mathrm{Hsp} 70$, and probably also for $H s p 68$ since inversion effects can extend as far as 1000 kilobases outside from breakpoints [56,57].

Following Santos et al. [58] the experimental flies were obtained from 54 crosses, which will be referred to as inbred (isogenic: $\mathrm{O}_{j}^{1} \times \mathrm{O}_{j}^{1}, \mathrm{O}_{j}^{2} \times \mathrm{O}_{j}^{2}, \ldots, \mathrm{O}_{j}^{6} \times \mathrm{O}_{j}^{6}$ with 18 crosses in total), or as outbred including both structural homokaryotypes $\left(\mathrm{O}_{j}^{1} \times \mathrm{O}_{j}^{2}, \mathrm{O}_{j}^{2} \times \mathrm{O}_{j}^{3}, \ldots, \mathrm{O}_{j}^{6} \times \mathrm{O}_{j}^{1}\right.$ with 18 cyclically permuted reciprocal crosses in total) and heterokaryotypes $\left(\mathrm{O}_{j}^{1} \times \mathrm{O}_{k}^{1}, \mathrm{O}_{j}^{2} \times \mathrm{O}_{k}^{2}, \ldots, \mathrm{O}_{j}^{6} \times \mathrm{O}_{k}^{6} ; j \neq k\right.$; with 18 reciprocal crosses in total). Two developmental temperatures were used in the experiment to study potentially important effects of phenotypic plasticity: $18^{\circ}$ $\mathrm{C}$ and $22^{\circ} \mathrm{C}$. The reason for this was the huge difference (about $7^{\circ} \mathrm{C}-8^{\circ} \mathrm{C}$ ) between our previous estimate of $T_{\mathrm{p}}$ (pooled average $16.6^{\circ} \mathrm{C}$; [34]) in D. subobscura flies raised at $18^{\circ} \mathrm{C}$, and that obtained by Huey and Pascual $\left(23.7^{\circ} \mathrm{C}\right.$; [12]) where flies were raised at $22^{\circ} \mathrm{C}$. Even though the flies assayed came from different sources south-western Europe in Rego et al. [34], and North America in Huey and Pascual [12] -, which could account for the observed difference because thermal responses can vary between populations [59], it remains to be seen whether developmental plasticity can affect estimates of thermal preference and heat tolerance. 


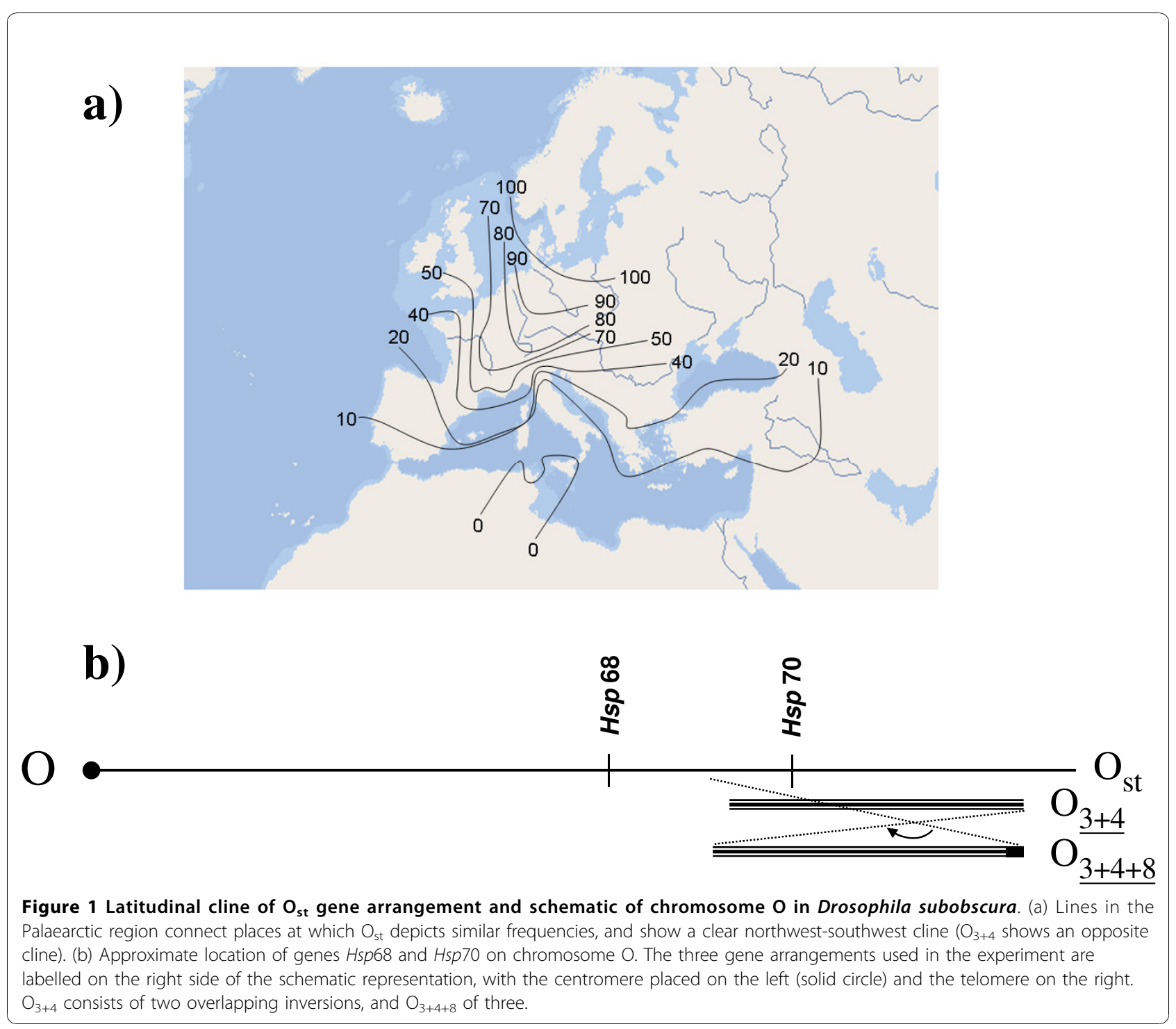

\section{Results}

\section{Association between thermal preference and knock out temperature}

The phenotypic correlation between $T_{\mathrm{p}}$ and $T_{\mathrm{ko}}$ was assessed from their partial correlation coefficient, holding constant the variables developmental temperature, sex, plate hour, and water bath (see Methods). In no case were the partial correlations statistically significant: inbred crosses $r_{T_{\mathrm{p}} \cdot T_{\mathrm{ko}}}=0.065, t=1.21, \mathrm{df}=347, P=$ 0.226; outbred crosses $r_{T_{\mathrm{p}} \cdot T_{\mathrm{ko}}}=-0.030, t=0.79, \mathrm{df}=$ $701, P=0.429$. Furthermore, as expected from the low values of the phenotypic correlation, the genetic (karyotypic) correlation for the outbred flies was also close to zero $\left(r_{k}=-0.068, P=0.914\right)$. The conclusion is that both traits are nearly orthogonal to each other (pooled
$\left.r_{T_{\mathrm{p}} \cdot T_{\mathrm{ko}}}=1.2 \times 10^{-4}, t=0.004, \mathrm{df}=1054, P=0.997\right)$ and, hence, they will be analyzed separately in what follows.

\section{Consanguinity and developmental effects a) Thermal preference}

Inbreeding and developmental temperature effects on $T_{\mathrm{p}}$ were simultaneously analyzed by contrasting isogenic $v s$. outbred homokaryotypic flies reared at both experimental temperatures (Figure 2). The factorial analysis of covariance (ANCOVA) only detected statistically significant differences for karyotypes, karyotype $\times$ inbreeding interaction, and karyotype $\times$ developmental temperature interaction effects (Table 1$)$. Average $( \pm \mathrm{SD}) T_{\mathrm{p}}$ was not different between rearing temperatures (flies reared at $18^{\circ} \mathrm{C}$ : $18.7^{\circ} \mathrm{C} \pm 4.1^{\circ} \mathrm{C}$; flies reared at $22^{\circ} \mathrm{C}: 18.8^{\circ} \mathrm{C} \pm 3.1^{\circ} \mathrm{C}$ ) or 

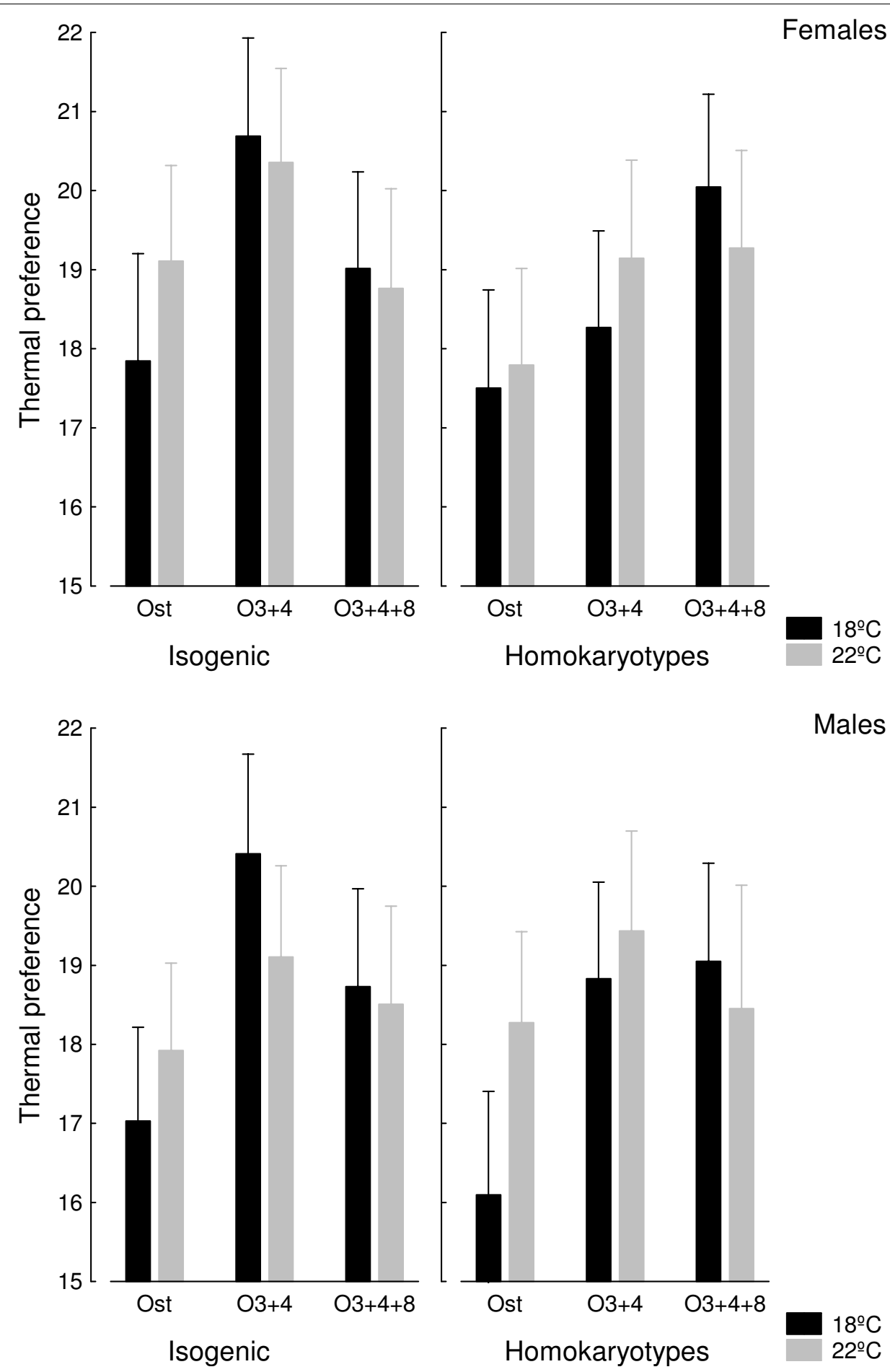

Figure 2 Inbreeding and temperature effects on thermal preference. Homokaryotipic averages for $T_{p}$ (in ${ }^{\circ} \mathrm{C}$ with $95 \%$ confidence intervals) in inbred (left panels) and outbred (right panels) crosses according to sex and developmental temperature.

sexes (females: $19.0^{\circ} \mathrm{C} \pm 3.6^{\circ} \mathrm{C}$; males: $18.5^{\circ} \mathrm{C} \pm 3.6^{\circ} \mathrm{C}$ ), although in this last case the effect was marginally nonsignificant $(P=0.053)$. Permutation tests (see Methods) corroborated that the three assayed karyotypes differ in $T_{\mathrm{p}}$ $(\mathrm{P}=0.001)$.
Scheffé post hoc tests using the mean square of the nested "cross" effect as the error term showed that the thermal preference of $\mathrm{O}_{\mathrm{st}} / \mathrm{O}_{\mathrm{st}}$ flies was significantly lower when compared to those of $\mathrm{O}_{3+4} / \mathrm{O}_{3+4}$ and $\mathrm{O}_{3+4}$ ${ }_{+8} / \mathrm{O}_{3+4+8}$ homokaryotypes, which did not differ between 
Table 1 Inbreeding and temperature effects on thermal preference

\begin{tabular}{lrrrr}
\hline Source of variation & d.f. & Mean Square & $\boldsymbol{F}$ & $\boldsymbol{P}$ \\
\hline Covariate (plate hour) & 1 & 25.502 & 2.07 & 0.151 \\
Karyotype $(\kappa)$ & 2 & 231.515 & 18.29 & $<0.001$ \\
Cross $\subset \kappa$ & 15 & 12.676 & 1.03 & 0.425 \\
Inbreeding $(l)$ & 1 & 30.514 & 2.47 & 0.116 \\
Temperature $(\tau)$ & 1 & 4.119 & 0.33 & 0.564 \\
Sex $(\varsigma)$ & 1 & 46.227 & 3.74 & 0.053 \\
$\kappa \times 1$ & 2 & 40.337 & 3.27 & 0.039 \\
$\kappa \times \tau$ & 2 & 40.031 & 3.24 & 0.040 \\
$\kappa \times \varsigma$ & 2 & 6.195 & 0.50 & 0.606 \\
$I \times \tau$ & 1 & 11.063 & 0.90 & 0.344 \\
$I \times \varsigma$ & 1 & 6.257 & 0.51 & 0.477 \\
$\tau \times \varsigma$ & 1 & 0.408 & 0.03 & 0.856 \\
$\kappa \times 1 \times \tau$ & 2 & 17.477 & 1.42 & 0.243 \\
$\kappa \times 1 \times \varsigma$ & 2 & 11.532 & 0.93 & 0.393 \\
$\kappa \times \tau \times \varsigma$ & 2 & 7.600 & 0.62 & 0.541 \\
$I \times \tau \times \varsigma$ & 1 & 12.123 & 0.98 & 0.322 \\
$\kappa \times I \times \tau \times \varsigma$ & 2 & 4.245 & 0.34 & 0.709 \\
Error & 717 & 12.346 & & \\
\hline
\end{tabular}

Flies raised from inbred (isogenic) and outbred crosses of Drosophila subobscura reared at $18^{\circ} \mathrm{C}$ and $22^{\circ} \mathrm{C}$. Karyotypes being compared are $\mathrm{O}_{\mathrm{st}} / \mathrm{O}_{\mathrm{st}}$ $\mathrm{O}_{3+4} / \mathrm{O}_{3+4}$, and $\mathrm{O}_{3+4+8} / \mathrm{O}_{3+4+8}$. ( $\subset$ means "nested in".)

them. The difference is consistent for both isogenic and outbred flies (Figure 2). From the present data we can conclude that the preferred temperature ranges or "set point" $\left(T_{\text {set }}\right)$ ranges (central $50 \%$ of preferred body temperatures; [60]) are bounded by $15.1^{\circ} \mathrm{C}-20.5^{\circ} \mathrm{C}$ for $\mathrm{O}_{\text {st }} / \mathrm{O}_{\text {st }}$ karyotypes, and $16.6^{\circ} \mathrm{C}-22.2^{\circ} \mathrm{C}$ for the other two karyotypes.

The karyotype $\times$ inbreeding interaction arises from the somewhat different behaviour between $\mathrm{O}_{\mathrm{st}} / \mathrm{O}_{\mathrm{st}}$ and $\mathrm{O}_{3+4} / \mathrm{O}_{3+4}$ karyotypes on one side, and $\mathrm{O}_{3+4+8} / \mathrm{O}_{3+4+8}$ on the other: for the first two karyotypes $T_{\mathrm{p}}$ was slightly higher in inbred crosses when compared to their outbred counterparts, whereas the opposite was true for the $\mathrm{O}_{3+4+8} / \mathrm{O}_{3+4+8}$ karyotype. Average $T_{\mathrm{p}}$ was, however, almost identical for inbred $\left(18.9^{\circ} \mathrm{C} \pm 3.6^{\circ} \mathrm{C}\right)$ and outbred $\left(18.5^{\circ} \mathrm{C} \pm 3.6^{\circ} \mathrm{C}\right)$ flies. On the other hand, $\mathrm{O}_{\text {st }} / \mathrm{O}_{\text {st }}$ flies raised at $22^{\circ} \mathrm{C}$ had a higher $T_{\mathrm{p}}$ than those raised at $18^{\circ}$ $\mathrm{C}$, but no clear trend was observed for $\mathrm{O}_{3+4} / \mathrm{O}_{3+4}$ and $\mathrm{O}_{3+4+8} / \mathrm{O}_{3+4+8}$ karyotypes.

\section{b) Knock out temperature}

Knock out temperatures are plotted in Figure 3. The ANCOVA (Table 2) detected statistically significant differences for the effects of rearing temperature and sex. Flies reared at $18^{\circ} \mathrm{C}$ had a higher $T_{\mathrm{ko}}$ than flies reared at $22^{\circ} \mathrm{C}$ (mean $\pm \mathrm{SD}: 33.3^{\circ} \mathrm{C} \pm 2.1^{\circ} \mathrm{C}$ vs. $32.6^{\circ} \mathrm{C} \pm 2.3^{\circ} \mathrm{C}$ ), and females had a higher $T_{\text {ko }}$ than males $\left(33.4^{\circ} \mathrm{C} \pm 1.9^{\circ}\right.$ $\mathrm{C}$ vs. $32.5^{\circ} \mathrm{C} \pm 2.4^{\circ} \mathrm{C}$ ). Even though $T_{\text {ko }}$ was slightly lower for the isogenic lines when compared to their outbred counterparts $\left(32.8^{\circ} \mathrm{C} \pm 2.2^{\circ} \mathrm{C}\right.$ vs. $33.1^{\circ} \mathrm{C} \pm$ $2.2^{\circ} \mathrm{C}$ ), inbreeding effects were clearly non-significant $(\mathrm{P}=0.136)$.

\section{Gene arrangement effects in the outbred lines a) Thermal preference}

The genetic and environmental (developmental temperature) contributions of chromosome $\mathrm{O}$ to $T_{\mathrm{p}}$ (and $T_{\mathrm{ko}}$; below) was assessed from the outbred crosses including all possible karyotypes. Outbred crosses are obviously more relevant to the real situation because inbred genotypes are homozygous for deleterious alleles, and also for alleles that might display heterozygote advantage in the original outbred population. The only statistically significant effects detected by the ANCOVA model (Table 3) were those arising from genetic differences among karyotypes (permutation tests corroborated that the three assayed karyotypes differ in $T_{\mathrm{p}} ; P=0.0018$ ) and sexes, with females having a higher $T_{\mathrm{p}}$ (mean \pm SD: $\left.18.7^{\circ} \mathrm{C} \pm 3.6^{\circ} \mathrm{C}\right)$ than males $\left(18.0^{\circ} \mathrm{C} \pm 3.6^{\circ} \mathrm{C}\right)$. As above, average $T_{\mathrm{p}}$ was slightly lower for flies reared at $18^{\circ} \mathrm{C}$ $\left(18.1^{\circ} \mathrm{C} \pm 4.0^{\circ} \mathrm{C}\right)$ than at $22^{\circ} \mathrm{C}\left(18.6^{\circ} \mathrm{C} \pm 3.2^{\circ} \mathrm{C}\right)$, but the difference was marginally non-significant $(P=0.069)$.

The linear contrast between the two $\mathrm{O}_{\mathrm{st}} / \mathrm{O}_{3+4}^{*}$ heterokaryotypes $\left(\mathrm{O}_{3+4}^{*}\right.$ pools into a single class the arrangements that share $\mathrm{O}_{3+4}$; see Methods) reveals that $\mathrm{O}_{\mathrm{st}} / \mathrm{O}_{3+4}$ and $\mathrm{O}_{\mathrm{st}} / \mathrm{O}_{3+4+8}$ flies displayed a similar average $T_{\mathrm{p}}\left(18.5^{\circ} \mathrm{C} \pm 3.8^{\circ} \mathrm{C}\right.$ vs. $18.0^{\circ} \mathrm{C} \pm 3.7^{\circ} \mathrm{C}$, respectively). However, some differences were detected among the three $\mathrm{O}_{3+4}^{*} / \mathrm{O}_{3+4}^{*}$ karyotypes, which can be attributed to some under-dominance because average $T_{\mathrm{p}}$ for $\mathrm{O}_{3+4} /$ $\mathrm{O}_{3+4+8}$ flies $\left(18.1^{\circ} \mathrm{C} \pm 3.4^{\circ} \mathrm{C}\right)$ was lower than that for the corresponding homokaryotypes $\left(\mathrm{O}_{3+4} / \mathrm{O}_{3+4}: 18.9^{\circ} \mathrm{C} \pm\right.$ $\left.3.5^{\circ} \mathrm{C} ; \mathrm{O}_{3+4+8} / \mathrm{O}_{3+4+8}: 19.3^{\circ} \mathrm{C} \pm 3.6^{\circ} \mathrm{C}\right)$. In any case, the main difference was between $\mathrm{O}_{\text {st }}$ and $\mathrm{O}_{3+4}^{*}$ carriers, with mainly additive genetic effects (Figure 4). As already indicated, $\mathrm{O}_{\mathrm{st}} / \mathrm{O}_{\text {st }}$ flies clearly preferred lower temperatures than $\mathrm{O}_{3+4} / \mathrm{O}_{3+4}$ or $\mathrm{O}_{3+4+8} / \mathrm{O}_{3+4+8}$ flies.

\section{b) Knock out temperature}

The ANCOVA for $T_{\text {ko }}$ (Table 4) did not detect any difference among karyotypes, in accordance with the previous findings for the inbred crosses. Similarly, the main differences arose between developmental temperature (flies reared at $18^{\circ} \mathrm{C}: 33.6^{\circ} \mathrm{C} \pm 1.9^{\circ} \mathrm{C}$; flies reared at $22^{\circ} \mathrm{C}$ : $32.8^{\circ} \mathrm{C} \pm 2.3^{\circ} \mathrm{C}$ ) and sex (females: $33.7^{\circ} \mathrm{C} \pm 1.8^{\circ} \mathrm{C}$; males: $32.7^{\circ} \mathrm{C} \pm 2.4^{\circ} \mathrm{C}$ ).

The genetic correlation between $T_{\mathrm{p}}$ and $T_{\mathrm{ko}}$ after pooling $\mathrm{O}_{3+4}$ and $\mathrm{O}_{3+4+8}$ was $r_{p}=-0.130(\mathrm{P}=0.917)$. Again, the conclusion is that these two traits are uncorrelated. Figure 4 plots the genotypic values in the 

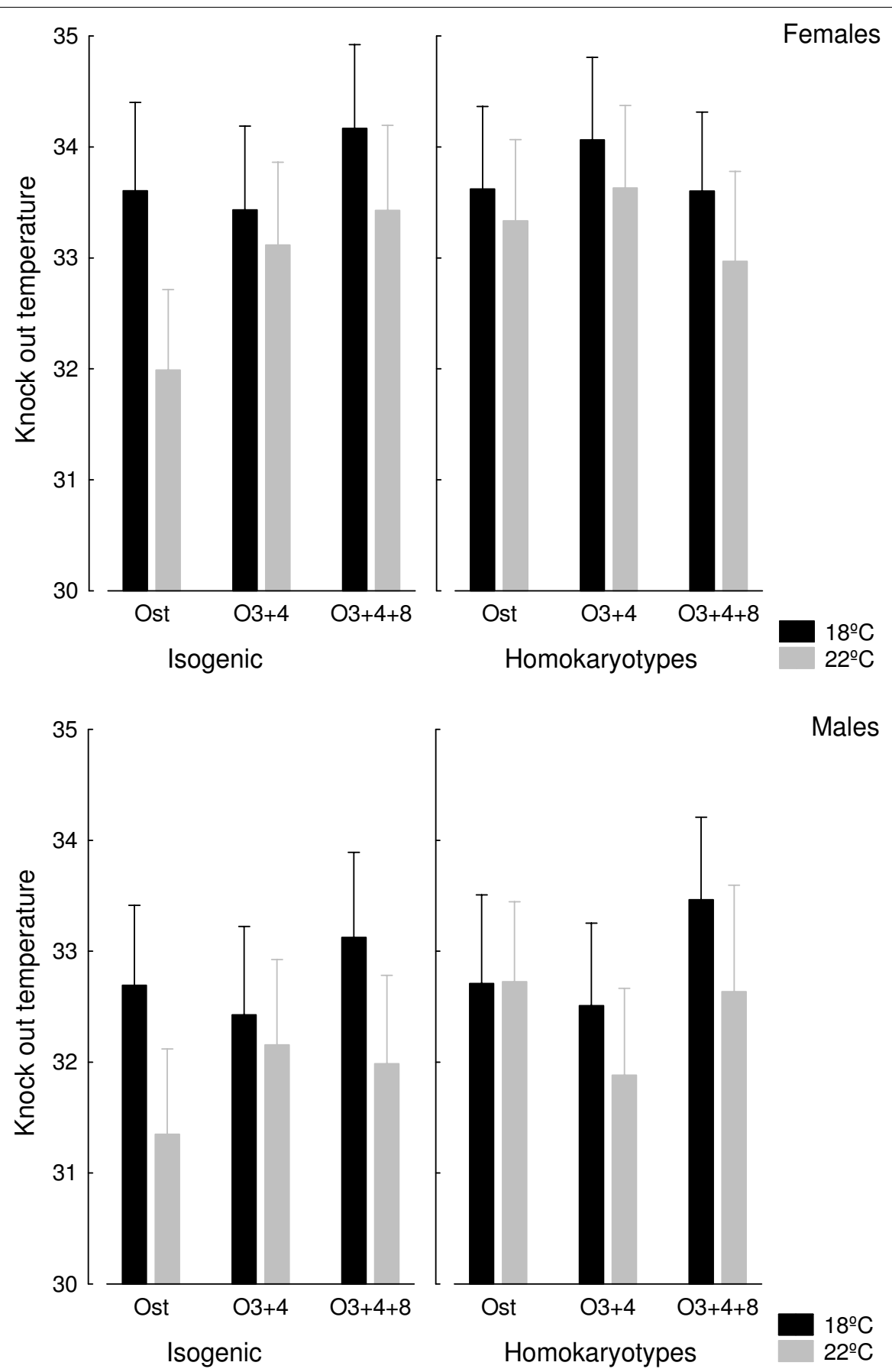

Figure 3 Inbreeding and temperature effects on knock out temperature. Homokaryotipic averages for $T_{\text {ko }}$ (in ${ }^{\circ} \mathrm{C}$ with $95 \%$ confidence intervals) in inbred (left panels) and outbred (right panels) crosses according to sex and developmental temperature.

additive-dominance scales for $T_{\mathrm{p}}$ and $T_{\mathrm{ko}}$, together with their statistical significance obtained from the appropriate contrasts (Table 3, 4).

\section{c) Average effects on thermal preference}

Our experiment only provides an estimation of the gene (chromosome $\mathrm{O}$ ) action on $T_{\mathrm{p}}$ and does not allow inferences to the base population. It is possible, however, to obtain estimates of the average effects, or "statistically additive effects", by taking into account the gene action and allelic (chromosome arrangement) frequencies in the natural populations [61]. Assuming that the chromosome arrangement effects are roughly the same along the cline (for a measure of climatic temperatures along the Palaearctic cline see Figure 1 in [62]), Table 5 gives 
Table 2 Inbreeding and temperature effects on knockout temperature

\begin{tabular}{lrrrr}
\hline Source of variation & d.f. & Mean Square & $\boldsymbol{F}$ & $\boldsymbol{P}$ \\
\hline Covariate (water bath) & 1 & 103.117 & 24.04 & $<0.001$ \\
Karyotype ( $\kappa)$ & 2 & 3.878 & 0.36 & 0.704 \\
Cross $\subset \kappa$ & 15 & 11.027 & 2.57 & 0.001 \\
Inbreeding $(l)$ & 1 & 9.538 & 2.22 & 0.136 \\
Temperature $(\tau)$ & 1 & 77.034 & 17.96 & $<0.001$ \\
Sex $(\varsigma)$ & 1 & 154.979 & 36.13 & $<0.001$ \\
$\kappa \times 1$ & 2 & 4.176 & 0.97 & 0.378 \\
$\kappa \times \tau$ & 2 & 1.999 & 0.47 & 0.628 \\
$\kappa \times \varsigma$ & 2 & 8.106 & 1.89 & 0.152 \\
$1 \times \tau$ & 1 & 1.047 & 0.24 & 0.621 \\
$1 \times \varsigma$ & 1 & 0.435 & 0.10 & 0.750 \\
$\tau \times \varsigma$ & 1 & 0.022 & 0.01 & 0.943 \\
$\kappa \times 1 \times \tau$ & 2 & 7.798 & 1.82 & 0.163 \\
$\kappa \times 1 \times \varsigma$ & 2 & 8.926 & 2.08 & 0.126 \\
$\kappa \times \tau \times \varsigma$ & 2 & 1.693 & 0.39 & 0.674 \\
$1 \times \tau \times \varsigma$ & 1 & 0.241 & 0.06 & 0.813 \\
$\kappa \times 1 \times \tau \times \varsigma$ & 2 & 0.159 & 0.04 & 0.964 \\
Error & 668 & 4.289 & & \\
\hline
\end{tabular}

Flies raised from inbred (isogenic) and outbred crosses of Drosophila subobscura reared at $18^{\circ} \mathrm{C}$ and $22^{\circ} \mathrm{C}$. Karyotypes being compared are $\mathrm{O}_{s t} / \mathrm{O}_{\text {st }}$ $\mathrm{O}_{3+4} / \mathrm{O}_{3+4}$, and $\mathrm{O}_{3+4+8} / \mathrm{O}_{3+4+8}$. ( $\mathrm{C}$ means "nested in".)

the average effects (females and males pooled) estimated from the frequencies of the different arrangements in European populations spanning about $17^{\circ}$ latitude $[52,54]$. The interpretation is that flies inheriting a $\mathrm{O}_{\text {st }}$ chromosome will choose a temperature ranging from around $0.31^{\circ} \mathrm{C}-0.45^{\circ} \mathrm{C}$ below the average temperature chosen by the population (conversely, flies carrying warm-climate chromosome arrangements will choose a temperature ranging from around $0.03^{\circ} \mathrm{C}-0.52^{\circ} \mathrm{C}$ above the average).

Combined with our previous results with chromosome A (which is the sex chromosome and additive values can be estimated using males' $T_{\mathrm{p}}$; [34]), where gene arrangement $A_{s t}$ exhibits a similar latitudinal pattern than $\mathrm{O}_{\mathrm{st}}$ and flies carrying $\mathrm{A}_{\mathrm{st}}$ also display a laboratory thermal preference towards colder temperature, the conclusion is that flies inheriting simultaneously $\mathrm{A}_{\mathrm{st}}$ and $\mathrm{O}_{\mathrm{st}}$ will choose temperatures ranging from approximately $0.5^{\circ} \mathrm{C}-1.0^{\circ} \mathrm{C}$ below the average (these estimates assume perfect additivity).

\section{Discussion}

The present results with isogenic lines and their crosses corroborate and extend our previous work with wild flies from south-western Europe [34]. They confirm that arrangements on chromosome $\mathrm{O}$ have a biometrical effect on thermal preference in a laboratory temperature gradient, with cold-climate $\mathrm{O}_{\text {st }}$ carriers displaying a lower $T_{p}$ than their warm-climate $\mathrm{O}_{3+4}$ and $\mathrm{O}_{3+4+8}$ counterparts. In addition, $T_{\mathrm{p}}$ and $T_{\mathrm{ko}}$ were again found to be uncorrelated, and we can now discard a potential genetic covariance between both traits arising from linkage disequilibrium between genes affecting thermal preference and candidate genes for heat shock resistance (i.e., Hsp 68 and Hsp 70; [42,43]) located inside of, or close to, the chromosome regions covered by the inversions analyzed here (see Background). In other words, we conclude that variation on $\mathrm{O}$ chromosome arrangements does not have any effect on knock out temperature (but see below). Note, however, that this does not imply that genes on chromosome $\mathrm{O}$ have no effect on

Table 3 Karyotype and temperature effects on thermal preference

\begin{tabular}{|c|c|c|c|c|}
\hline Source of variation & d.f. & Mean Square & $F$ & $P$ \\
\hline Covariate (plate hour) & 1 & 147.947 & 11.84 & $<0.001$ \\
\hline Karyotype $(\kappa)$ & 5 & 60.774 & 4.97 & 0.002 \\
\hline $\mathrm{O}_{\mathrm{st}} / \mathrm{O}_{3+4}^{*}$ & 1 & 0.853 & 0.07 & 0.793 \\
\hline $\mathrm{O}_{3+4}^{*+1} / \mathrm{O}_{3+4}^{*}$ & 2 & 42.884 & 3.51 & 0.043 \\
\hline $\mathrm{O}_{\mathrm{st}} / \mathrm{O}_{\mathrm{st}}, \mathrm{O}_{\mathrm{st}} / \mathrm{O}_{3+4}^{*}, \mathrm{O}_{3+4}^{*} / \mathrm{O}_{3+4}^{*}$ & 2 & 106.330 & 8.70 & 0.001 \\
\hline additive effect & 1 & 205.854 & 16.85 & $<0.001$ \\
\hline dominance effect & 1 & 3.532 & 0.29 & 0.595 \\
\hline Cross $\subset \kappa$ & 30 & 12.220 & 0.98 & 0.502 \\
\hline Temperature $(\tau)$ & 1 & 41.328 & 3.31 & 0.069 \\
\hline $\operatorname{Sex}(\varsigma)$ & 1 & 91.221 & 7.30 & 0.007 \\
\hline$\kappa \times \tau$ & 5 & 19.791 & 1.58 & 0.162 \\
\hline$\kappa \times \varsigma$ & 5 & 10.805 & 0.86 & 0.505 \\
\hline$\tau \times \varsigma$ & 1 & 4.948 & 0.40 & 0.529 \\
\hline$\kappa \times \tau \times \varsigma$ & 5 & 8.863 & 0.71 & 0.617 \\
\hline Error & 691 & 12.498 & & \\
\hline
\end{tabular}

Flies raised from outbred crosses of Drosophila subobscura reared at $18^{\circ} \mathrm{C}$ and $22^{\circ} \mathrm{C}$. Karyotypes being compared are $\mathrm{O}_{5 t} / \mathrm{O}_{5 t}, \mathrm{O}_{3+4} / \mathrm{O}_{3+4}, \mathrm{O}_{3+4+8} / \mathrm{O}_{3+4+8}, \mathrm{O}_{5 t} / \mathrm{O}_{3+4}$, $\mathrm{O}_{\mathrm{st}} / \mathrm{O}_{3+4+8}$ and $\mathrm{O}_{3+4} / \mathrm{O}_{3+4+8} . \mathrm{O}_{3+4}^{*}$ stands for $\mathrm{O}_{3+4}+\mathrm{O}_{3+4+8}$. ( $\mathrm{C}$ means "nested in".) 


\section{Females}

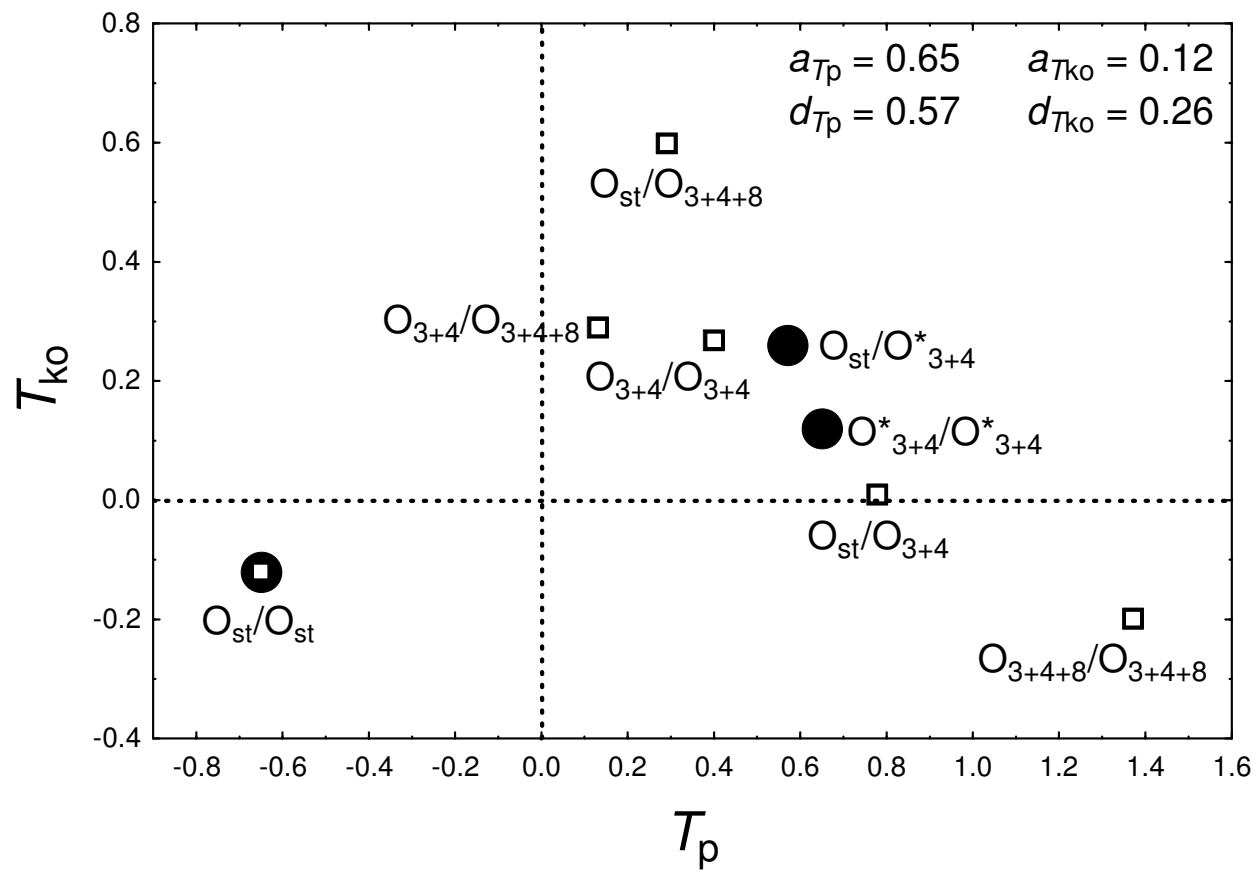

Males

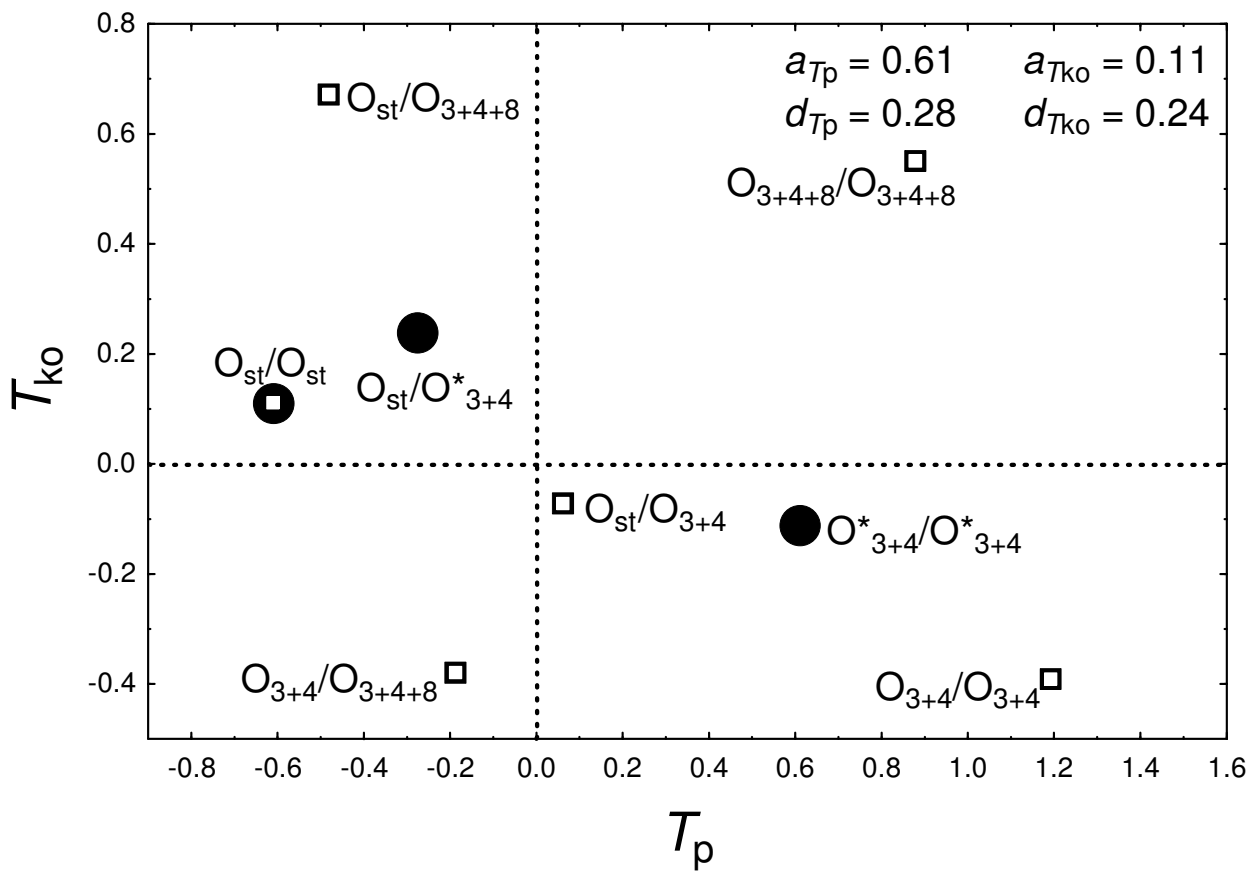

Figure 4 Karyotypic values in the additive-dominance scale. Deviation values for thermal preference $\left(T_{\mathrm{p}}\right)$ and knockout temperature $\left(T_{\mathrm{ko}}\right)$ were measured after pooling arrangements $\mathrm{O}_{3+4}$ and $\mathrm{O}_{3+4+8}$ into a single class $\left(\mathrm{O}_{3+4}^{*}\right)$, and the coordinate point $(0,0)$ was taken as the midparent (i.e., the average of $T_{p}$ and $T_{\text {ko }}$ for the two karyotypes $\mathrm{O}_{\mathrm{st}} / \mathrm{O}_{\mathrm{st}}$ and $\mathrm{O}_{3+4}^{*} / \mathrm{O}_{3+4}^{*}$ ). Females (upper panel) and males (lower panel) are plotted separately because the interaction karyotype $\times$ sex was statistically significant for $T_{\text {ko }}$ (Table 4$)$. In the original scale the $(0,0)$ point corresponds to an average $T_{\mathrm{p}}$ of $18.31^{\circ} \mathrm{C}$ for females and $17.91^{\circ} \mathrm{C}$ for males, and an average $T_{\text {ko }}$ of $33.58^{\circ} \mathrm{C}$ for females and $32.61^{\circ} \mathrm{C}$ for males. Open squares give the values for all six karyotypes to appreciate their dispersion from the midparent, as well as their dispersion from the pooled $\mathrm{O}_{\mathrm{st}} / \mathrm{O}_{3+4}^{*}$ and $\mathrm{O}_{3+4}^{*} / \mathrm{O}_{3+4}^{*}$ karyotypes (black circles). Statistical significance for additive $\left(a_{T_{\mathrm{p}}}, a_{T_{\mathrm{ko}}}\right)$ and dominance $\left(d_{T_{\mathrm{p}}}, d_{T_{\mathrm{ko}}}\right)$ effects are given in Tables 3 and 4. Note also that the phenotypic $\left(r_{T_{\mathrm{p}}} \cdot T_{\mathrm{ko}}=-0.030\right)$ and genetic $\left(r_{k}=-0.068, r_{p}=-0.130\right.$; see Methods) correlations were nonsignificantly different from zero (see text for details). 
Table 4 Karyotype and temperature effects on knockout temperature

\begin{tabular}{|c|c|c|c|c|}
\hline Source of variation & d.f. & Mean Square & $F$ & $P$ \\
\hline Covariate (water bath) & 1 & 101.377 & 25.87 & $<0.001$ \\
\hline Karyotype $(\kappa)$ & 5 & 4.295 & 0.57 & 0.724 \\
\hline $\mathrm{O}_{\mathrm{st}} / \mathrm{O}_{3+4}^{*}$ & 1 & 11.598 & 1.52 & 0.228 \\
\hline $\mathrm{O}_{3+4}^{*} / \mathrm{O}_{3+4}^{*}$ & 2 & 0.016 & 0.002 & 0.998 \\
\hline $\mathrm{O}_{\mathrm{st}} / \mathrm{O}_{\mathrm{st}}, \mathrm{O}_{\mathrm{st}} / \mathrm{O}_{3+4}^{*}, \mathrm{O}_{3+4}^{*} / \mathrm{O}_{3+4}^{*}$ & 2 & 4.872 & 0.64 & 0.536 \\
\hline additive effect & 1 & 0.015 & 0.001 & 0.965 \\
\hline dominance effect & 1 & 8.632 & 1.13 & 0.296 \\
\hline Cross $\subset \kappa$ & 30 & 7.641 & 1.95 & 0.002 \\
\hline Temperature $(\tau)$ & 1 & 107.075 & 27.33 & $<0.001$ \\
\hline $\operatorname{Sex}(\varsigma)$ & 1 & 180.874 & 46.16 & $<0.001$ \\
\hline$\kappa \times \tau$ & 5 & 7.576 & 1.93 & 0.087 \\
\hline$\kappa \times \varsigma$ & 5 & 8.777 & 2.24 & 0.049 \\
\hline$\tau \times \varsigma$ & 1 & 1.650 & 0.42 & 0.517 \\
\hline$\kappa \times \tau \times \varsigma$ & 5 & 2.329 & 0.59 & 0.704 \\
\hline Error & 654 & 3.918 & & \\
\hline
\end{tabular}

Flies raised from outbred crosses of Drosophila subobscura reared at $18^{\circ} \mathrm{C}$ and $22^{\circ} \mathrm{C}$. Karyotypes being compared are $\mathrm{O}_{s t} / \mathrm{O}_{5 t}, \mathrm{O}_{3+4} / \mathrm{O}_{3+4}, \mathrm{O}_{3+4+8} / \mathrm{O}_{3+4+8}, \mathrm{O}_{5 t} / \mathrm{O}_{3+4+8}$, and $\mathrm{O}_{3+4} / \mathrm{O}_{3+4+8}$. $\mathrm{O}_{3+4}^{*}$ stands for $\mathrm{O}_{3+4}+\mathrm{O}_{3+4+8}$. ( $\subset$ means "nested in".)

$T_{\text {ko }}$ (actually, statistically significant differences were detected among crosses within karyotypes; Table 4); it simply indicates that any allelic variation of putative genes influencing this trait is not in linkage disequilibrium with inversions on this chromosome.

The new findings were: $(i)$ a lack of inbreeding depression for both $T_{\mathrm{p}}$ and $T_{\mathrm{ko}}$; $(\mathrm{ii})$ a lack of phenotypic plasticity for $T_{\mathrm{p}}$ according to the temperature at which the flies were raised $\left(18^{\circ} \mathrm{C}\right.$ and $\left.22^{\circ} \mathrm{C}\right)$; and (iii) a substantial effect of developmental temperature on $T_{\mathrm{ko}}$. The absence of inbreeding depression for $T_{\mathrm{p}}$ agrees with the genetic analysis from outbred flies, where a dominance effect after pooling chromosome arrangements $\mathrm{O}_{3+4}$ and
$\mathrm{O}_{3+4+8}$ into a single class $\left(\mathrm{O}_{3+4}^{*}\right)$ was absent (Table 3; note that the differences detected among the three $\mathrm{O}_{3+4}^{*} / \mathrm{O}_{3+4}^{*}$ karyotypes, and attributed to some underdominance, could not be appreciated in the inbreeding analysis because it only included inbred and outbred homokaryotypes). On the other hand, the lack of inbreeding depression for $T_{\mathrm{ko}}$ is expected and does not mean anything here, simply because no "gene" effects linked to chromosomal arrangements on chromosome $\mathrm{O}$ were detected. At first sight this might be surprising because a well-characterized cellular defence mechanism once environmental temperature approaches the upper

Table 5 Average effect of chromosome 0 on thermal preferences $\left({ }^{\circ} \mathrm{C}\right)$

\begin{tabular}{|c|c|c|c|c|c|}
\hline \multirow[b]{2}{*}{ Population } & \multirow[b]{2}{*}{ Coordinates } & \multicolumn{2}{|c|}{ Frequency } & \multicolumn{2}{|c|}{ Average effect } \\
\hline & & $\mathrm{O}_{\mathrm{st}}$ & $\mathrm{O}_{3+4}^{*}$ & $\mathrm{O}_{\mathrm{st}}$ & Rest \\
\hline Málaga (Spain) & $36^{\circ} 43^{\prime} \mathrm{N}-4^{\circ} 25^{\prime} \mathrm{W}$ & 0.080 & 0.407 & -0.4506 & 0.0392 \\
\hline Punta Umbría (Spain) & $37^{\circ} 10^{\prime} \mathrm{N}-6^{\circ} 57^{\prime} \mathrm{W}$ & 0.066 & 0.410 & -0.4494 & 0.0318 \\
\hline Calviá (Spain) & $39^{\circ} 33^{\prime} \mathrm{N}-2^{\circ} 29^{\prime} \mathrm{E}$ & 0.057 & 0.590 & -0.4485 & 0.0271 \\
\hline Riba-roja (Spain) & $39^{\circ} 33^{\prime} \mathrm{N}-0^{\circ} 34^{\prime} \mathrm{W}$ & 0.148 & 0.324 & -0.4530 & 0.0787 \\
\hline Queralbs (Spain) & $42^{\circ} 13^{\prime} \mathrm{N}-2^{\circ} 10^{\prime} \mathrm{E}$ & 0.290 & 0.493 & -0.4395 & 0.1795 \\
\hline Lagrasse (France) & $43^{\circ} 05^{\prime} \mathrm{N}-2^{\circ} 37^{\prime} \mathrm{E}$ & 0.330 & 0.590 & -0.4312 & 0.2124 \\
\hline Montpellier (France) & $43^{\circ} 36^{\prime} \mathrm{N}-3^{\circ} 53^{\prime} \mathrm{E}$ & 0.362 & 0.557 & -0.4232 & 0.2401 \\
\hline Villars (France) & $45^{\circ} 26^{\prime} \mathrm{N}-0^{\circ} 44^{\prime} \mathrm{E}$ & 0.389 & 0.581 & -0.4155 & 0.2645 \\
\hline Leuk (Switzerland) & $46^{\circ} 19^{\prime} \mathrm{N}-7^{\circ} 39^{\prime} \mathrm{E}$ & 0.595 & 0.365 & -0.3267 & 0.4800 \\
\hline Vienna (Austria) & $48^{\circ} 13^{\prime} \mathrm{N}-16^{\circ} 22^{\prime} \mathrm{E}$ & 0.625 & 0.270 & -0.3095 & 0.5158 \\
\hline Tübingen (Germany) & $48^{\circ} 32^{\prime} \mathrm{N}-9^{\circ} 04^{\prime} \mathrm{E}$ & 0.606 & 0.351 & -0.3205 & 0.4930 \\
\hline Louvain-la-Neuve (Belgique) & $50^{\circ} 43^{\prime} \mathrm{N}-4^{\circ} 37^{\prime} \mathrm{E}$ & 0.397 & 0.540 & -0.4130 & 0.2719 \\
\hline Groningen (The Netherlands) & $53^{\circ} 13^{\prime} \mathrm{N}-6^{\circ} 35^{\prime} \mathrm{E}$ & 0.502 & 0.405 & -0.3733 & 0.3763 \\
\hline
\end{tabular}

$\mathrm{O}_{3+4}^{*}$ pools gene arragements $\mathrm{O}_{3+4}$ and $\mathrm{O}_{3+4+8}$ used in the present work. Together with $\mathrm{O}_{\text {st, }}$ their combined frequency is $\geq 0.90$ in central European populations and drops to approximately 0.50 in south-western Europe, where arrangement $\mathrm{O}_{3+4+7}$ is also frequent. However, from our previous data [34] no difference in $T_{p}$ is detected between $\mathrm{O}_{3+4+7}$ and $\mathrm{O}_{3+4}^{*}$, which justifies their pooling and allows estimating average effects assuming two gene arrangements: $\mathrm{O}_{\mathrm{st}}$ and the rest. Gene arrangement frequencies where taken from the "new collections" in Solé et al. [52] and Balanyà et al. [54]. 
thermal limits is the heat shock response, and in D. melanogaster the major inducible heat shock protein Hsp70 appears to be the primary protein involved in thermotolerance [45,63]. Recent work, however, questions the pervasive role of $\mathrm{Hsp} 70$ in the mediation of the heat stress response and suggests that it may be life-stage specific, being important in larvae but not in adults [64]. Our results are apparently consistent with the lack of association between Hsp70 and adult heat resistance (but see further discussion below), although also raise a caveat to the conclusion that there is no covariance between $T_{\mathrm{p}}$ and $T_{\mathrm{ko}}$. Thus, it could be the case that Hsp70 variation across karyotypes is associated with juvenile tolerance to heat stress, an important trait in Drosophila particularly in summer when larval feeding patches can become lethally hot [65]. This possibility warrants further analysis.

An important concern here is that Hsp70 production might not be inducible in the dynamic experimental protocol we used to estimate upper thermal tolerance, where temperature increased $0.1^{\circ} \mathrm{C} \mathrm{min}^{-1}$. One apparently compelling reason for this is that the estimated maximum thermal limits that $D$. melanogaster can tolerate decrease from approximately $39.9^{\circ} \mathrm{C}$ with heating rate $0.5^{\circ} \mathrm{C} \mathrm{min}{ }^{-1}$ to $38.7^{\circ} \mathrm{C}$ with heating rate $0.1^{\circ} \mathrm{C} \mathrm{min}{ }^{-1}$ [66], a puzzling result because slower heating rates should allow individuals to acclimatize to new temperatures and also because slow heating rates pre-exposes individuals to non-lethal high temperatures ("hardening"), which increases heat shock resistance [10]. We have recently discussed why these conflicting outcomes arise, and suggest that the contribution of other stressors (e.g. higher desiccation in long thermal tolerance assays associated with slow warming rates) can potentially overshadow thermal acclimation effects in dynamic assays with varying heating rates [67]. In other words, we challenge the idea that induced thermotolerance does not occur in dynamic assays with slow heating rates. At this stage this is just speculative because Hsp70 production was not measured in our flies, but the problem is important because Drosophila adults are likely to experience slow heating rates in nature of 0.06 $-0.1^{\circ} \mathrm{C} \min ^{-1}[66,68]$ and further empirical studies are required to explain the apparently inconsistent findings.

The pooled average $T_{\mathrm{p}}$ here was (mean $\left.\pm \mathrm{SD}\right) 18.4^{\circ} \mathrm{C}$ $\pm 3.6^{\circ} \mathrm{C}\left(T_{\text {set }}: 15.4^{\circ} \mathrm{C}-21.2^{\circ} \mathrm{C}\right.$; these figures include only outbred lines) and about the same at both rearing temperatures. The difference with our previous estimate for wild-flies from Adraga $\left(16.6^{\circ} \mathrm{C}, T_{\text {set }}: 12.4^{\circ} \mathrm{C}-20.4^{\circ} \mathrm{C}\right.$; [34]) does not seem to be overreached, and could be partially explained by the fact that the present flies were genetically homogeneous for all chromosomes from the ch-cu marker strain but chromosome $\mathrm{O}$ (recall that the sex chromosome A also had a significant effect on $T_{\mathrm{p}}$; [34]).
This strain has a long history of maintenance at $18^{\circ} \mathrm{C}$ in the laboratory. In any case, our estimates remain substantially lower than that from Huey and Pascual $\left(23.7^{\circ} \mathrm{C}, T_{\text {set }}: 21.2^{\circ} \mathrm{C}-25.9^{\circ} \mathrm{C}\right.$; [12]), and the difference cannot be accounted by flies' rearing temperature. No reasonable explanation for the discrepancy can be offered at this moment, but the additional result that developmental temperature substantially affected $T_{\text {ko }}$ makes us confidently conclude that our estimates are indeed closer to the actual $T_{\mathrm{p}}$ of the species. Flies reared at $22^{\circ} \mathrm{C}$ showed lower heat resistance than their counterparts reared at $18^{\circ} \mathrm{C}\left(32.8^{\circ} \mathrm{C}\right.$ vs. $33.6^{\circ} \mathrm{C}$; outbred lines $)$, which could be a consequence of their smaller size due to the inverse relationship between body size and developmental temperature $[69,70]$. However, resistance to heat does not seem to be associated with body size [71] - we have also analyzed the association between $T_{\mathrm{ko}}$ and wing size from our previous experiment where both traits were recorded $[30,34]$ and found no relationship whatsoever (results not shown). Most likely, $22^{\circ} \mathrm{C}$ was a suboptimal and potentially stressful temperature for our flies, making them to be weaker and less resistant to the heat shock. Note, however, that this conclusion might not be extrapolated to wild flies that harbour higher levels of genetic variability than our chromosomal lines.

To interpret the interplay between thermal preference and heat stress resistance, an understanding of the environmental temperatures experienced by $D$. subobscura along climatic gradients is required. As far as we are aware, the only data available on $T_{\mathrm{b}}$ for active flies along a latitudinal gradient (spanning $12^{\circ}$ ) come from recent work by Huey and Pascual [12] in western North America. They found that mean $T_{\mathrm{b}}$ varies by as much as $21^{\circ} \mathrm{C}$ (from $8^{\circ} \mathrm{C}$ to $29^{\circ} \mathrm{C}$ ), and that the temporal activity of flies during the day did not match predictions from optimal temperature regulation or desiccation avoidance. Temperatures of maximum activity in summer (Figure 2 in [12]) - when wild flies are smaller probably due to their higher developmental temperatures and/or crowding conditions [72]; and crowding is known to affect adult thermal stress resistance in Drosophila [73] - are dangerously close to the $T_{\mathrm{ko}}$ obtained here for the outbred flies raised at $22^{\circ} \mathrm{C}$. This suggests that active D. subobscura flies can experience extreme conditions in the wild, and one would expect flies' activity to be correlated with heat resistance under these conditions if behaviour and physiology were coadapted. Some evidence indicates that diurnal activity patterns in summer can vary according to inversion polymorphism, and chromosome arrangements on the $\mathrm{O}$ chromosome seem to behave as expected from our data: $\mathrm{O}_{\mathrm{st}}$ is more frequent towards the evening while chromosomes carrying gene arrangement $\mathrm{O}_{3+4}$ are most frequently sampled at midday [74]. This behavioural thermoregulation, 
however, would not confer less susceptibility to high temperatures because the genetic basis of both traits does not seem to allow for the building up of "coadaptation". It is well known from basic population genetics theory that genetic covariance between traits can arise when alleles at different loci are associated (linkage disequilibrium), and this critically depends on relatively low recombination rates [75]. The lack of association between $T_{\mathrm{p}}$ and $T_{\mathrm{ko}}$ in $D$. subobscura is fully consistent with their genetic basis as independently segregating chromosomes are involved [34]. Yet, a correlation between these traits can be expected at the interpopulational level due to patterns of correlated selection (rather than genetic correlations) across a latitudinal gradient because of the congruent latitudinal clinal variation for chromosome arrangements on the $\mathrm{E}$ (which influences $T_{\mathrm{ko}}$ [34]), and on the $\mathrm{A}$ and $\mathrm{O}$ chromosomes (which influence $T_{\mathrm{p}}$ [[34], this work]).

We now speculate that the mismatch between $T_{\mathrm{p}}$ and $T_{\text {ko }}$ could apparently generate an interesting dynamics in the population frequencies of different chromosome arrangements on chromosome O. Suppose the daily activity of flies in the warmest months of the year follows the previously described pattern; that is, flies carrying gene arrangement $\mathrm{O}_{3+4}$ are more active at midday and, therefore, have a higher risk of a heat shock than $\mathrm{O}_{\text {st }}$ and are selected against. On the other hand, assuming $T_{\mathrm{p}}$ corresponds closely with temperatures that maximize fitness $\mathrm{O}_{3+4}$ flies likely enjoy a fitness advantage in summer. The net effect would be a compromise between "behaviour unresponsiveness" and general performance, which means that chromosome arrangements on chromosome $\mathrm{O}$ may or may not cycle seasonally according to average environmental temperature (i.e., $\mathrm{O}_{3+4}$ could be expected to increase in frequency in summer and decrease in winter if general performance is what matters). Interestingly, both patterns have been detected: consistent seasonal cycling at a north-western population in Spain [8] and apparently no seasonal variation at a north-eastern population also in Spain [76]. The point here is that parallel seasonal changes should also be detected for chromosome A since it also affects $T_{\mathrm{p}}$ [34]. In accordance with this prediction, no seasonal cycling was detected for chromosome A in the northeastern population, but unfortunately no information is available for the other population because chromosome $\mathrm{O}$ was the only chromosome scored. It would be very interesting to see what happens for chromosome A in the cycling population.

\section{Conclusions}

For ectotherms facing spatiotemporal variation in environmental temperature theory predicts that a coevolution between thermal preference and physiological performance can occur [1]. In the widespread species D. subobscura behavioural thermoregulation and heat tolerance are "coadapted" in the sense that flies carrying cold-climate (warm-climate) chromosome arrangements tend to choose colder (warmer) temperatures and have lower (higher) heat stress tolerance [34]. We have analyzed the genetic basis of these thermal traits using isochromosomal lines for the $\mathrm{O}$ chromosome. This chromosome was known to affect thermal preference [34], and also harbours several genes involved in the heat shock response (Hsp68 and Hsp70) [42,43]. These genes are located inside of, or close to, the chromosome regions covered by inversions that show conspicuous northwest-southwest latitudinal clines in Palaearctic populations, as well as seasonal fluctuations that are in agreement with the latitudinal patterns [22]. Our results corroborate that arrangements on chromosome $\mathrm{O}$ affect adult thermal preference: flies inheriting the cold-climate $\mathrm{O}_{\text {st }}$ chromosome are predicted to choose a temperature around $0.31^{\circ} \mathrm{C}-0.45^{\circ} \mathrm{C}$ below the average temperature chosen by the population and, conversely, flies inheriting the warm-climate $\mathrm{O}_{3+4}$ and $\mathrm{O}_{3+4+8}$ chromosomes are expected to choose a temperature ranging from around $0.03^{\circ} \mathrm{C}-0.52^{\circ} \mathrm{C}$ above the average. However, these chromosome arrangements did not have any differential effect on adult heat tolerance. We conclude that thermal preference and heat tolerance in D. subobscura appear to be genetically independent and, therefore, any latitudinal correlation between both traits would likely reflect a pattern of correlated selection across populations rather than within-population genetic correlations.

\section{Methods}

\section{Origin of flies and experimental procedures}

D. subobscura wild flies were collected near Barcelona $\left(41^{\circ} 43^{\prime} \mathrm{N}, 2^{\circ} 13^{\prime} \mathrm{E}\right)$ in October 2007 . More than 200 isofemale lines were derived and used to obtain isochromosomal lines for the $\mathrm{O}$ chromosome in an otherwise homogeneous genetic background following standard protocols [77]. Briefly, one offspring male from each isofemale line was crossed to three or four virgin females from the ch-cu marker strain, which is homozygous for the morphological recessive markers on the O chromosome cherry eyes (ch) and curled wings $(\mathrm{cu})$ and the chromosomal arrangement $\mathrm{O}_{3+4}$. A single wild-type male from each cross was repeatedly backcrossed to three or four ch-cu females for at least five generations in order to homogenize the genetic background, and the chromosomal arrangement carried by the wild chromosome was identified after the second backcross. To derive the isochromosomal lines, wild-type males from each line were crossed with the $\mathrm{Va} / \mathrm{Ba}$ balancer stock [78], which has the same genetic background as the 
ch-cu strain. Once obtained, the isochromosomal lines were genotyped for 13 microsatellite loci located on the O chromosome to check that no recombination events occurred during the different crosses. The 18 independent isochromosomal lines used in this study (see Experimental settings) were found to be homozygous for all the loci. The lines were kept at $18^{\circ} \mathrm{C}$ (12:12 light/ dark cycle) in 130-mL bottles with low adult density (around 20 pairs/bottle) to standardize the rearing conditions before egg collections.

To obtain the experimental flies, all 54 crosses (inbred and outbred) were performed at $18^{\circ} \mathrm{C}$ by mating 4 daysold virgin males and females from the corresponding isochromosomal lines. After six days the males were discarded and the females (an equal number from each reciprocal cross in the outbred combinations) were transferred to egg-laying chambers containing fresh food and charcoal colouring. Eggs were placed in vials (45 eggs/vial containing $6 \mathrm{~mL}$ of food) at two rearing temperatures: $18^{\circ} \mathrm{C}$ and $22^{\circ} \mathrm{C}$. Non-anaesthetized emerging flies were stored in bottles at low adult density and used to evaluate laboratory thermal preference $\left(T_{\mathrm{p}}\right)$ and knock out temperature ( $\left.T_{\mathrm{ko}}\right)$ for each cross (see below). All fly handling was done at room temperature using $\mathrm{CO}_{2}$ anaesthesia only to sort virgin flies and to place females in the egg-laying chambers.

\section{Thermal preference behaviour in a laboratory gradient and heat resistance}

Laboratory $T_{\mathrm{p}}$ was measured as previously described [34]. Briefly, adult flies (about 7 days old) were individually placed in separate lanes on an aluminium base plate where a thermal gradient with temperatures ranging from $11^{\circ} \mathrm{C}$ to $29^{\circ} \mathrm{C}$ was generated. Adults were given approximately $1 \mathrm{~h}$ to adjust, and afterwards their positions were recorded four times every $10 \mathrm{~min}$. We used the median of the four measurements to estimate $T_{\mathrm{p}}$ of each fly. Measurements were performed in a room with constant temperature $\left(22^{\circ} \mathrm{C}-23^{\circ} \mathrm{C}\right)$, and the flies were assayed under white light illumination. This protocol renders a repeatable assessment of flies' thermal preferences [34]. After the thermal preference assay, each fly was gently removed from the lane and individually placed in a vial with fresh food for the subsequent assay of heat stress tolerance.

One day after measurements of thermal preference flies were assayed for heat resistance also as previously described [34]. Adults were individually placed in sealed empty vials and immersed in water-baths at $T_{\min }=24^{\circ}$ C. Every $10 \mathrm{~min}$ individuals were scored for mobility (fly active or knocked out) and the temperature of the water was increased by $\Delta T=+1^{\circ} \mathrm{C}$. The procedure was repeated until the water-baths reached $T_{\max }$, defined as the temperature when the last active fly was knocked out $\left(T_{\max }=38^{\circ} \mathrm{C}\right.$ was the upper limit in the assays; median $T_{\max }=33^{\circ} \mathrm{C}$ ). For each fly $T_{\text {ko }}$ was estimated as the temperature taken to knock it out (defined as the onset of muscle spasms; [79]).

\section{Statistical methods}

The experimental setup was devised to assay one male and one female from each cross and temperature per day (five blocks) for both $T_{\mathrm{p}}$ and $T_{\mathrm{ko}}$, amounting to 1,080 flies in total. Some mishaps (e.g. individuals flew away or just died during the assays) were, however, unavoidable and the final data set contains a few more than or a few less than 10 flies in several crosses (the harmonic means of flies per cross and temperature were: $T_{\mathrm{p}}$ assay, 5.04 females and 4.80 males; $T_{\text {ko }}$ assay, 4.89 females and 4.37 males). Statistical analysis with and without block design qualitatively yielded the same results. Therefore, to simplify matters blocks were not considered in the linear models below.

\section{a) Consanguinity and temperature effects}

Inbreeding and temperature effects were simultaneously analyzed by contrasting isogenic vs. outbred homokaryotypic flies reared at both developmental temperatures. The linear model used was:

$$
\begin{gathered}
T_{\mathrm{p}(i j k l m n)}=\mu+\kappa_{i}+C_{j(i)}+\tau_{k}+\iota_{l}+\varsigma_{m}+\kappa \tau_{i k}+\kappa \iota_{i l}+\kappa \varsigma_{i m}+\tau \iota_{k l}+\tau \varsigma_{k m}+\ldots \\
+l \varsigma_{l m}+\kappa \tau t_{i k l}+\kappa \tau \varsigma_{i k m}+\kappa \iota \varsigma_{i l m}+\tau \iota \varsigma_{k l m}+\kappa \tau \iota \varsigma_{i k l m}+\varepsilon_{i j k l m n}
\end{gathered}
$$

where $\mu$ is the overall grand mean, $\kappa_{i}$ is the fixed effect of the karyotype $(i=1,2,3), C_{j(i)}$ is the random effect of the $j$ th cross $(j=1,2, \ldots, 6)$ within karyotype $i$, $\tau_{k}$ is the fixed effect of the developmental temperature $\left(18^{\circ} \mathrm{C}\right.$ or $\left.22^{\circ} \mathrm{C}\right), \iota_{l}$ is the fixed effect of inbreeding (isogenic or outbred homokaryotypic flies), $\varsigma_{m}$ is the fixed effect of sex, and $\varepsilon_{i j k l m n}$ is the residual error associated with the thermal preference $\left(T_{\mathrm{p}}\right)$ of the $n$th fly from the $m$ th sex with the $i$ th karyotype from the $j$ th cross that was derived from the $\iota$ th group of crosses and assayed at the $k$ th temperature. The covariate plate-hour was also introduced in the model to control for differences in circadian activity since several trials were conducted during each day. A similar linear model was used for knock out temperature, also introducing water-bath as a covariate since $T_{\mathrm{ko}}$ was assessed in different water-baths.

Notice that for the main effect "karyotype" the linear model (1) can be conveniently reduced to the following two-level nested ANOVA model:

$$
T_{\mathrm{p}(i j k)}=\mu+\kappa_{i}+C_{j(i)}+e_{i j k}
$$

where the sum of squares for the error term $e_{i j k}$ is simply the sum of the sum of squares for the remainder terms in (1). The usefulness of this model reduction is to efficiently perform randomization tests to test the 
null hypothesis about karyotype effects in a randomized (i.e., random assignment) experiment [80]. Permutation tests are far less sensitive to the presence of outliers than parametric tests. The null hypothesis of no karyotype effect was tested here after performing random permutations among replicate and selection temperature for the among selection temperature $F$-statistics. Each test used 10,000 random permutations.

\section{b) Karyotype variation}

To asses the effect of $\mathrm{O}$ chromosome karyotypes on $T_{\mathrm{p}}$ and $T_{\text {ko }}$ we have focused in the outbred crosses, including both structural homo- and heterokaryotypes. The linear model used was similar to (1) including the fixed effect of karyotype $\left(\kappa_{i} ; i=1,2, \ldots, 6\right)$, the random effect of cross within karyotypes $\left(C_{j(i)} ; j=1,2, \ldots, 6\right)$, the fixed effect of developmental temperature, and the fixed effect of sex. The covariate plate-hour was also introduced in the model. As above, a similar linear model was used for knock out temperature, also introducing water-bath as a covariate.

In the original Palaearctic populations chromosome arrangements $\mathrm{O}_{3+4}$ and $\mathrm{O}_{3+4+8}$ have a higher frequency at lower latitudes than arrangement $\mathrm{O}_{\mathrm{st}}$, and the converse is true a higher latitudes $[35,36]$. For this reason, the variation explained by the six karyotypes was further decomposed after pooling the first two arrangements into a single class $\left(\mathrm{O}_{3+4}^{*}\right)$ as follows: between the two $\mathrm{O}_{\text {st }} / \mathrm{O}_{3+4}^{*}$ heterokaryotypes; among the three $\mathrm{O}_{3+4}^{*} / \mathrm{O}_{3+4}^{*}$ karyotypes; and among $\mathrm{O}_{\mathrm{st}} / \mathrm{O}_{\mathrm{st}}, \mathrm{O}_{\mathrm{st}} / \mathrm{O}_{3+4}^{*}$, $\mathrm{O}_{3+4}^{*} / \mathrm{O}_{3+4}^{*}$. The karyotypic values for $T_{\mathrm{p}}$ and $T_{\mathrm{ko}}$ were also estimated in the additive-dominance scale $[81,82]$ after pooling the two chromosome arrangements that share $\mathrm{O}_{3+4}$ (each comparison or contrast between two means has one degree of freedom).

The genetic correlation between $T_{\mathrm{p}}$ and $T_{\mathrm{ko}}$ can be approached as indicated in Betrán et al. [26]. Assuming that the components of the between karyotypes sums of squares and cross-products (SSCP) hypothesis matrix $\left(\mathbf{H}_{k}\right)$ are entirely genetic in origin, the correlation coefficient between the means of all six outbred karyotypes is given by:

$$
r_{k}=\frac{\mathbf{H}_{k}(1,2)}{\sqrt{\mathbf{H}_{k}(1,1) \mathbf{H}_{k}(2,2)}},
$$

where $\mathbf{H}_{k}(1,2)$ is the off-diagonal element (sum of products of karyotype averages), and $\mathbf{H}_{k}(i, i)$ is a diagonal element (sum of squares of karyotypes averages) for the $i$ th variable. This correlation coefficient is obviously an approximation to the genetic correlation because the $\mathbf{H}_{k}$ matrix also contains a fraction of the variation among the isogenic lines used to obtain the outbred flies (see Experimental settings). The correlation coefficient can be tested as:

$$
t=r \sqrt{\frac{k-2}{1-r^{2}}}
$$

where $k$ is the number of karyotypes [83]. After pooling the arrangements that share arrangement $\mathrm{O}_{3+4}$ into a single class, we can now obtain the new hypothesis matrix $\mathbf{H}_{p}$. The correlation coefficient between the pooled averages can be estimated as:

$$
r_{p}=\frac{\mathbf{H}_{p}(1,2)}{\sqrt{\mathbf{H}_{k}(1,1) \mathbf{H}_{k}(2,2)}} .
$$

The square of this correlation can be interpreted as that fraction of the total variation among karyotypes that is explained by $\mathrm{O}_{\mathrm{st}} / \mathrm{O}_{\mathrm{st}}, \mathrm{O}_{\mathrm{st}} / \mathrm{O}_{3+4}^{*}, \mathrm{O}_{3+4}^{*} / \mathrm{O}_{3+4}^{*}$.

\section{c) Computer software for statistical analysis}

The computer programs used for statistical data analyses were MATLAB algebra program environment (ver. 7.0.4 [84]) together with the collection of tools supplied by the Statistics Toolbox. The statistical software packages STATISTICA version 9 [85] and SPSS version 15 [86] were also used.

\section{Acknowledgements}

We thank three anonymous reviewers for comments on the manuscript. OD is supported by a pre-doctoral fellowship (BES-2007-17438) from the Ministerio de Educación y Ciencia (Spain). CR is supported by a postdoctoral fellowship (SFRH/BPD/39998/2007) from Fundação para a Ciência e a Tecnologia (Portugal). GC is supported by a pre-doctoral fellowship (BES2007-15096) from the Ministerio de Educación y Ciencia (Spain). ELR is supported by a Ramón y Cajal contract from the Ministerio de Ciencia e Innovación (Spain). This research was supported by grants CGL2006-13423C01 and CGL2006-13423-C02-02 from the Ministerio de Ciencia y Tecnología (Spain); CGL2009-12912-C03-01, CGL2010-15395 and BFU2009-07564 from the Ministerio de Ciencia e Innovación; and 2009SGR 636 from Generalitat de Catalunya to the Grup de Biologia Evolutiva.

\section{Author details}

${ }^{1}$ Departament de Genètica i de Microbiologia, Grup de Biologia Evolutiva (GBE), Universitat Autònoma de Barcelona, 08193 Bellaterra (Barcelona), Spain. ²Departamento de Ciências Agrárias, Azorean Biodiversity GroupCITAA, Universidade dos Açores, Terra-Chã, 9701-851 Angra do Heroísmo, Portugal. ${ }^{3}$ Departament de Genètica, Grup de Biologia Evolutiva (GBE), Facultat de Biologia, Universitat de Barcelona, Diagonal 645, 08071 Barcelona, Spain. ${ }^{4}$ Institut de Recerca de la Biodiversitat (IRBio), Universitat de Barcelona, 08071 Barcelona, Spain.

\section{Authors' contributions}

OD, GC, JB, MP and MS sampled flies from the natural population and setup isofemale lines. OD and GC obtained the isochromosomal lines. JB helped in gene arrangement identification. GC and MP assayed the isochromosomal lines for microsatellites. OD, CR and GC carried out experimental crosses and egg collections. OD, GC, JB, and MS assayed the flies for thermal preference and knock out temperature. OD, CR, ELR and MS conceived the study. OD, $C R$, and MS carried out statistical analyses and drafted the manuscript. All authors read and approved the final manuscript. 
Received: 12 July 2010 Accepted: 25 November 2010

Published: 25 November 2010

\section{References}

1. Angilletta MJ: Thermal Adaptation. A Theoretical and Empirical Synthesis Oxford: Oxford Univ Press; 2009.

2. Stevenson RD: The relative importance of behavioral and physiological adjustments controlling body temperature in terrestrial ectotherms. Am Nat 1985, 126:362-386

3. Casey TM, Hegel JR: Caterpillar setae: insulation for an ectotherm. Science 1981, 214:1131-1133

4. Kingsolver JG, Watt WB: Thermoregulatory strategies in Colias butterflies: thermal stress and limits to adaptation in temporally varying environments. Am Nat 1983, 121:32-35.

5. Willmer PG, Unwin S: Field analyses of insect heat budget: reflectance, size and heating rates. Oecologia 1981, 50:250-255.

6. Huey RB, Hertz PE, Sinervo B: Behavioral drive versus behavioral inertia in evolution: a null model approach. Am Nat 2003, 161:357-366.

7. Dobzhansky Th: Genetics of the Evolutionary Process New York: Columbia Univ Press; 1970

8. Rodríguez-Trelles F, Alvarez G, Zapata C: Time-series analysis of seasonal changes of the $\mathrm{O}$ inversion polymorphism of Drosophila subobscura. Genetics 1996, 142:179-187.

9. Coyne JA, Bundgaard J, Prout T: Geographic variation of tolerance to environmental stress in Drosophila pseudoobscura. Am Nat 1983, 122:474-488

10. Hoffmann AA, Sørensen JG, Loeschcke V: Adaptation of Drosophila to temperature extremes: bringing together quantitative and molecular approaches. J Therm Biol 2003, 28:175-216.

11. Hoffmann AA: Physiological climatic limits in Drosophila: patterns and implications. J Exp Biol 2010, 213:870-880.

12. Huey RB, Pascual M: Partial thermoregulatory compensation along a latitudinal cline in a rapidly evolving invasive species. Drosophila subobscura in North America. Ecology 2009, 90:1715-1720.

13. Sinclair BJ, Vernon P, Klok CJ, Chown SL: Insects at low temperatures: an ecological perspective. Trends Ecol Evol 2003, 18:257-262.

14. Hofmann GE, Todgham AE: Living in the now: physiological mechanisms to tolerate a rapidly changing environment. Annu Rev Physiol 2010, 72:127-145.

15. Huey RB, Bennett AF: Phylogenetic studies of coadaptation: preferred temperatures versus optimal performance temperatures of lizards. Evolution 1987, 41:1098-1115.

16. Angilletta MJ, Bennett AF, Guderley H, Navas CA, Seebacher F, Wilson RS: Coadaptation: a unified principle in evolutionary thermal biology. Physiol Biochem Zool 2006, 79:282-294.

17. Mayr E: Animal Species and Evolution Cambridge, Harvard Univ Press; 1963.

18. Ayala FJ, Serra L, Prevosti A: A grand experiment in evolution Drosophila subobscura colonization of the Americas. Genome 1989, 31:246-255.

19. Hoffmann AA, Weeks AR: Climatic selection on genes and traits after 100 year-old invasion: a critical look at the temperate-tropical clines in Drosophila melanogaster from eastern Australia. Genetica 2007, 129:133-147.

20. Huey RB, Gilchrist GW, Carlson ML, Berrigan D, Serra L: Rapid evolution of a geographical cline in size in an introduced fly. Science 2000, 287:308-309.

21. Balanyà J, Serra L, Gilchrist GW, Huey RB, Pascual M, Mestres F, Solé E: Evolutionary pace of chromosomal polymorphism in colonizing populations of Drosophila subobscura: an evolutionary time series. Evolution 2003, 57:1837-1845.

22. Rezende EL, Balanyà J, Rodríguez-Trelles F, Rego C, Fragata I, Matos M Serra L, Santos M: Climate change and chromosomal inversions in Drosophila subobscura. Clim Res 2010, 43:103-114.

23. Gilchrist G, Jeffers L, West B, Folk D, Suess J, Huey RB: Clinal patterns of desiccation and starvation resistance in ancestral and invading populations of Drosophila subobscura. Evol Appl 2008, 1:513-23.

24. Calboli FCF, Gilchrist GW, Partridge L: Different cell size and cell number contribution in two newly established and one ancient body size cline of Drosophila subobscura. Evolution 2003, 57:566-573.

25. Gilchrist GW, Huey RB, Serra L: Rapid evolution of wing size clines in Drosophila subobscura. Genetica 2001, 112-113:273-286.
26. Betrán E, Santos M, Ruiz A: Antagonistic pleiotropic effect of secondchromosome inversions on body size and early life-history traits in Drosophila buzzatii. Evolution 1998, 52:144-154.

27. Etterson JR, Shaw RG: Constraint to adaptive evolution in response to global warming. Science 2001, 294:151-154.

28. Fontdevila A, Zapata C, Alvarez G, Sanchez L, Méndez J, Enriquez I: Genetic coadaptation in the chromosomal polymorphism of Drosophila subobscura. I. Seasonal changes of gametic disequilibrium in a natural population. Genetics 1983, 105:935-955.

29. Rodríguez-Trelles F: Seasonal cycles of allozyme-by-chromosomalinversion gametic disequilibrium in Drosophila subobscura. Evolution 2003, 57:839-848.

30. Fragata I, Balanyà J, Rego C, Matos M, Rezende EL, Santos M: Contrasting patterns of phenotypic variation linked to chromosomal inversions in native and colonizing populations of Drosophila subobscura. J Evol Biol 2010, 23:112-123.

31. Nosil P, Crespi BJ, Sandoval CP, Kirkpatrick M: Migration and the genetic covariance between habitat preference and performance. Am Nat 2006, 167:E66-E78

32. Duckworth RE: The role of behavior in evolution: a search for mechanism. Evol Ecol 2009, 23:513-531.

33. Dillon ME, Wang G, Garrity PA, Huey RB: Thermal preference in Drosophila. J Therm Biol 2009, 34:109-119.

34. Rego C, Balanyà J, Fragata I, Matos M, Rezende EL, Santos M: Clinal patterns of chromosomal inversion polymorphisms in Drosophila subobscura are partly associated with thermal preferences and heat stress resistance. Evolution 2010, 64:385-397.

35. Menozzi P, Krimbas CB: The inversion polymorphism of Drosophila subobscura revisited: synthetic maps of gene arrangement frequencies and their interpretation. J Evol Biol 1992, 5:625-641.

36. Krimbas CB: The inversion polymorphism of Drosophila subobscura. In Drosophila Inversion Polymorphism. Edited by: Krimbas CB, Powell JR. Boca Raton: CRC Press; 1992:127-220

37. Sperlich D, Feuerbach-Mravlag H, Lange P, Michaelidis A, PentzosDaponte A: Genetic load and viability distribution in central and marginal populations of Drosophila subobscura. Genetics 1977, 86:835-848.

38. Pegueroles C, Araúz PA, Pascual M, Mestres F: A recombination survey using microsatellites: the $\mathrm{O}$ chromosome of Drosophila subobscura. Genetica 2010, 138:795-804

39. Powell JR: Progress and Prospects in Evolutionary Biology. The Drosophila Model New York: Oxford Univ Press; 1997.

40. Santos J, Serra L, Solé E, Pascual M: FISH mapping of microsatellite loci from Drosophila subobscura and its comparison to related species. Chromosome Res 2010, 18:213-226.

41. Laayouni H, García-Franco F, Chávez-Sandoval BE, Trotta V, Beltran S, Corominas M, Santos M: Thermal evolution of gene expression profiles in Drosophila subobscura. BMC Evol Biol 2007, 7:42.

42. Moltó MD, Pascual L, Martínez-Sebastián MJ, de Frutos R: Genetic analysis of the heat shock response in three Drosophila species of the obscura group. Genome 1992, 35:870-880.

43. Cuenca JB, Galindo MI, Saura AO, Sorsa V, de Frutos R: Ultrastructure of regions containing homologous loci in polytene chromosomes of Drosophila melanogaster and Drosophila subobscura. Chromosoma 1998, 107:113-126.

44. Kunze-Mühl $E$, Müller $E$ : Weitere Untersuchungen über die chromosomale Struktur und natürlichen Strukturtypen von D. subobscura. Chromosoma 1958, 9:559-570.

45. Parsell DA, Taulien J, Lindquist S: The role of heat-shock proteins in thermotolerance. Phil Trans Roy Soc London Series B 1993, 339:279-286.

46. Krebs RA: A comparison of Hsp70 expression and thermotolerance in adults and larvae of three Drosophila species. Cell Stress Chaperones 1999, 4:243-249.

47. Bettencourt BR, Kim I, Hoffmann AA, Feder ME: Response to natural and laboratory selection at the Drosophila hsp70 genes. Evolution 2002, 56:1796-1801.

48. McColl G, Hoffmann AA, McKechnie SW: Response of two heat shock genes to selection for knockdown heat resistance in Drosophila melanogaster. Genetics 1996, 143:1615-1627.

49. Santos M, Iriarte PF, Céspedes W, Balanyà J, Fontdevila A, Serra L: Swift laboratory thermal evolution of wing shape (but not size) in Drosophila 
subobscura and its relationship with chromosomal inversion polymorphism. J Evol Biol 2004, 17:841-855.

50. Santos M, Céspedes W, Balanyà J, Trotta V, Calboli FCF, Fontdevila A, Serra L: Temperature-related genetic changes in laboratory populations of Drosophila subobscura: evidence against simple climatic-based explanations for latitudinal clines. Am Nat 2005, 165:258-273.

51. Santos M: Evolution of total net fitness in thermal lines: Drosophila subobscura likes it "warm". J Evol Biol 2007, 20:2361-2370.

52. Solé E, Balanyà J, Sperlich D, Serra L: Long-term changes in the chromosomal inversion polymorphism of Drosophila subobscura. I. Mediterranean populations from southwestern Europe. Evolution 2002, 56:830-835

53. Prevosti A: Chromosomal inversion polymorphism in the southwestern range of Drosophila subobscura distribution area. Genetica 1974, 45:111-124.

54. Balanyà J, Solé E, Oller JM, Sperlich D, Serra L: Long-term changes in the chromosomal inversion polymorphism of Drosophila subobscura. II. European populations. J Zool Syst Evol Res 2004, 42:191-201.

55. Munté A, Rozas J, Aguadé M, Segarra C: Chromosomal inversion polymorphism leads to extensive genetic structure: a multilocus survey in Drosophila subobscura. Genetics 2005, 69:1573-1581.

56. Andolfatto P, Depaulis F, Navarro A: Inversion polymorphism and nucleotide variability in Drosophila. Genet Res 2001, 77:1-8.

57. Laayouni H, Hasson E, Santos M, Fontdevila A: Inversion polymorphism and nucleotide variability in different regions of the secondchromosome in Drosophila buzzatii. Mol Biol Evol 2003, 20:931-944.

58. Santos M, Iriarte PF, Cespedes W: Genetics and geometry of canalization and developmental stability in Drosophila subobscura. BMC Evol Biol 2005, $5: 7$

59. Yamamoto AH: Temperature preference of Drosophila immigrans and $D$. virilis: Intra- and inter-population genetic variation. Jpn J Genet 1994, 69:67-76.

60. Hertz PE, Huey RB, Stevenson RD: Evaluating temperature regulation by field-active ectotherms: the fallacy of the inappropriate question. Am Nat 1993, 142:796-818.

61. Falconer DS, Mackay TF: Introduction to Quantitative Genetics. 4 edition. Essex, England: Longman; 1996.

62. Balanyà J, Oller JM, Huey RB, Gilchrist GW, Serra L: Global genetic change tracks global climate warming in Drosophila subobscura. Science 2006, 313:1773-1775.

63. Sørensen JG, Kristensen TN, Loeschcke V: The evolutionary and ecological role of heat shock proteins. Ecol Lett 2003, 6:1025-1037.

64. Jensen LT, Cockerell FE, Kristensen TN, Rako L, Loeschcke V, McKechnie SW, Hoffmann AA: Adult heat tolerance variation in Drosophila melanogaster is not related with Hsp70 expression. J Exp Zool 2010, 313A:35-44.

65. Feder ME, Blair N, Figueras H: Oviposition site selection: unresponsiveness of Drosophila to cues of potential thermal stress. Anim Behav 1997, 53:585-588.

66. Chown SL, Jumbam KR, Sørensen JG, Terblanche JS: Phenotypic variance, plasticity and heritability estimates of critical thermal limits depend on methodological context. Funct Ecol 2009, 23:133-140.

67. Rezende EL, Tejedo M, Santos M: Estimating the adaptive potential of critical thermal limits: methodological problems and evolutionary implications. Funct Ecol 2010

68. Mitchell KA, Hoffmann AA: Thermal ramping rate influences evolutionary potential and species differences for upper thermal limits in Drosophila. Funct Ecol 2010, 24:694-700.

69. Moreteau B, Morin J-P, Gibert P, Petavy G, Pla E, David JR: Evolutionary changes of nonlinear reaction norms according to thermal adaptation: a comparison of two Drosophila species. C R Acad Sci Paris 1997, 320:833-841.

70. Santos M, Brites D, Laayouni L: Thermal evolution of pre-adult life history traits, geometric size and shape, and developmental stability in Drosophila subobscura. J Evol Biol 2006, 19:2006-2021.

71. Bubli OL, Imasheva AG, Loeschcke V: Selection for knockdown resistance to heat in Drosophila melanogaster at high and low larval densities. Evolution 1998, 52:619-625.

72. Kari JS, Huey RB: Size and seasonal temperature in free-ranging Drosophila subobscura. J Therm Biol 2000, 25:267-272.
73. Sørensen JG, Loeschcke V: Larval crowding in Drosophila melanogaster induces Hsp70 expression, and leads to increased adult longevity and adult thermal stress resistance. J Insect Physiol 2001, 47:1301-1307.

74. Savković V, Stamenkovic-Radak M, Andjelkovic M: Diurnal variability of gene arrangement frequencies in Drosophila subobscura populations from two habitats. J Zool Syst Evol Res 2004, 42:208-214.

75. Hedick PW: Genetics of Populations. 2 edition. Boston: Jones and Bartlett Publ; 2000.

76. de Frutos $R$, Prevosti A: Temporal changes of chromosomal polymorphism in natural populations of Drosophila subobscura. Genetica 1984, 63:181-187.

77. Iriarte FP, Céspedes W, Santos M: Quantitative-genetic analysis of wing form and bilateral asymmetry in isochromosomal lines of Drosophila subobscura using the Procrustes methods. J Genet 2003, 82:95-113.

78. Mestres F, Pegueroles G, Prevosti A, Serra L: Colonization of America by Drosophila subobscura: lethal genes and the problem of the $\mathrm{O5}$ inversion. Evolution 1990, 44:1823-1836.

79. Lutterschmidt WI, Hutchinson VH: The critical thermal maximum: data to support the onset of spasms as the definitive end point. Can J Zool 1997, 75:1553-1560.

80. Edgington ES: Randomization Tests. 3 edition. New York: Marcel Dekker; 1995.

81. Mather K, Jinks JL: Introduction to Biometrical Genetics London: Chapman and Hall; 1977.

82. Mather K, Jinks JL: Biometrical Genetics: The Study of Continuous Variation. 3 edition. London: Chapman and Hall; 1982.

83. Sokal RR, Rohlf FJ: Biometry. 3 edition. New York: Freeman; 1995

84. MathWorks Inc: Matlab, V. 7.5.0.342 (R2007b). The Language of Technical Computing 2007 [http://www.mathworks.com].

85. StatSoft Inc: STATISTICA (data analysis software system), version 9. 2009 [http://www.statsoft.com].

86. SPSS Inc: SPSS for Windows 2006 [http://www.spss.com].

\section{doi:10.1186/1471-2148-10-363}

Cite this article as: Dolgova et al: Genetic constraints for thermal coadaptation in Drosophila subobscura. BMC Evolutionary Biology 2010 10:363.

\section{Submit your next manuscript to BioMed Central and take full advantage of:}

- Convenient online submission

- Thorough peer review

- No space constraints or color figure charges

- Immediate publication on acceptance

- Inclusion in PubMed, CAS, Scopus and Google Scholar

- Research which is freely available for redistribution 